Check for updates

Cite this: RSC Adv., 2019, 9, 35735

\title{
Reorientation dynamics and ion diffusivity of neat dimethylimidazolium dimethylphosphate probed by NMR spectroscopy $\dagger$
}

\begin{abstract}
Christoph Wiedemann, (D) *a Günter Hempel ${ }^{\mathrm{b}}$ and Frank Bordusa*a
NMR spectroscopy at two magnetic field strengths was employed to investigate the dynamics of dimethylimidazolium dimethylphosphate $\left(\left[\mathrm{C}_{1} \mathrm{C}_{1} \mathrm{IM}\right]\left[\left(\mathrm{CH}_{3}\right)_{2} \mathrm{PO}_{4}\right]\right) . \quad\left[\mathrm{C}_{1} \mathrm{C}_{1} \mathrm{IM}\right]\left[\left(\mathrm{CH}_{3}\right)_{2} \mathrm{PO}_{4}\right]$ is a low-melting, halogen-free ionic liquid comprising of only methyl groups. ${ }^{13} \mathrm{C}$ spin-lattice relaxation rates as well as self-diffusion coefficients were measured for $\left[\mathrm{C}_{1} \mathrm{C}_{1} \mathrm{IM}\right]\left[\left(\mathrm{CH}_{3}\right)_{2} \mathrm{PO}_{4}\right]$ as a function of temperature. The rotational correlation times, $\tau_{\mathrm{c}}$, for the cation and the anion were obtained from the ${ }^{13} \mathrm{C}$ spin-lattice relaxation rates. Although from a theoretical point of view cations and anions are similar in size, they show different reorientation mobilities and diffusivities. The self-diffusion coefficients and the rotational correlation times were related to the radii of the diffusing spheres. The analysis reveals that the radii of the cation and the anion, respectively, are different from each other but constant at temperatures ranging from 293 to $353 \mathrm{~K}$. The experimental results are rationalised by a discrete and individual cation and anion diffusion. The $\left[\left(\mathrm{CH}_{3}\right)_{2} \mathrm{PO}_{4}\right]^{-}$anion reorients faster compared to the cation but diffuses significantly slower indicating the formation of anionic aggregates. Relaxation data were acquired with standard liquid and magic-angle-spinning NMR probes to estimate residual dipolar interactions, chemical shift anisotropy or differences in magnetic susceptibility within the sample.
\end{abstract}

Received 23rd September 2019 Accepted 28th October 2019

DOI: 10.1039/c9ra07731f

rsc.li/rsc-advances
A deeper understanding of IL properties at a molecular or even atomic level is of vital interest with respect to the rational design of novel ILs or the previous knowledge about the suitability of ILs for a desired process. Facing the plethora of various types and classes of ILs, a comprehensive characterization of the physicochemical properties is, realistically seen, only possible for selected cation-anion combinations. The prediction of the physicochemical characteristics, and, maybe even more importantly, the potential performance for novel task-driven ILs based on structure-function relationships of known cation-anion combinations is a great challenge. Hence, a combined approach integrating spectroscopic, experimental and theoretical/computational methods is required to broaden our understanding of ILs and the cationic-anionic interplay among each other and with solutes as well.

Nuclear magnetic resonance (NMR) is a powerful spectroscopic techniques for studying compounds or molecular systems at an atomic level. Despite some experimental limitations (e.g. high IL viscosity, radio frequency absorption due to high concentration of charged particles resulting in sample heating, detuned frequency channels, or with respect to solutes the suppression of IL solvent signals) it has been frequently shown that ILs can be thoroughly investigated by NMR. ${ }^{13-18}$ By means of NMR spectroscopy different types of information on IL structure and dynamics are readily accessible by probing chemical shifts, nuclear Overhauser effects (NOEs), relaxation times or self-diffusion coefficients. The atomic composition of
${ }^{a}$ Institute of Biochemistry and Biotechnology, Charles Tanford Protein Center, Martin Luther University Halle-Wittenberg, Kurt-Mothes-Str. 3a, D-06120 Halle (Saale), Germany.E-mail: christoph.wiedemann@biochemtech.uni-halle.de; frank.bordusa@ biochemtech.uni-halle.de

${ }^{b}$ Institute of Physics, Martin Luther University Halle-Wittenberg, Betty-Heimann-Str. 7, D-06120 Halle (Saale), Germany

$\dagger$ Electronic supplementary information (ESI) available. See DOI: 10.1039/c9ra07731f 
ILs offers an intrinsic set of NMR active spin-1/2 nuclei, such as ${ }^{1} \mathrm{H},{ }^{13} \mathrm{C},{ }^{15} \mathrm{~N},{ }^{19} \mathrm{~F},{ }^{31} \mathrm{P}$, suitable for investigation. In order to understand IL properties as a whole and the single contributions of the IL cation and anion respectively, to the observable IL properties, the characterization of the molecular dynamics is of great interest. The relaxation properties and diffusivity of selected imidazolium-based ILs have been successfully investigated recently using NMR spectroscopy. ${ }^{19-28}$

Here, we examine and analyse ${ }^{13} \mathrm{C}$ spin-lattice relaxation times $\left(T_{1}\right.$, relaxation rate: $\left.R_{1}=1 / T_{1}\right)$ as well as self-diffusion coefficients of the ionic liquid dimethylimidazolium dimethylphosphate $\left(\left[\mathrm{C}_{1} \mathrm{C}_{1} \mathrm{IM}\right]\left[\left(\mathrm{CH}_{3}\right)_{2} \mathrm{PO}_{4}\right]\right.$, Fig. 1$)$ over a wide temperature range. In contrast to other imidazolium-based ILs, $\left[\mathrm{C}_{1} \mathrm{C}_{1} \mathrm{IM}\right]\left[\left(\mathrm{CH}_{3}\right)_{2} \mathrm{PO}_{4}\right]$ is a low-melting (liquid at room temperature), halogen-free IL comprising only methyl groups. The relaxation data were acquired with standard liquid probes at two magnetic field strengths and compared with data collected with high-resolution magic-angle spinning (HR-MAS) probes.

\section{Materials and methods}

\section{Samples}

$\left[\mathrm{C}_{1} \mathrm{C}_{1} \mathrm{IM}\right]\left[\left(\mathrm{CH}_{3}\right)_{2} \mathrm{PO}_{4}\right]$ was purchased from IoLiTec $\mathrm{GmbH}$ (Heilbronn, Germany) in highest available purity $(\geq 98 \%)$ and used without further purification. The purity was confirmed by ${ }^{1} \mathrm{H}$ and ${ }^{13} \mathrm{C}$ NMR spectroscopy. The ${ }^{1} \mathrm{H}$ and ${ }^{13} \mathrm{C}$ NMR spectra $\left[\mathrm{C}_{1} \mathrm{C}_{1} \mathrm{IM}\right]\left[\left(\mathrm{CH}_{3}\right)_{2} \mathrm{PO}_{4}\right]$ are depicted in Fig. S1 and S2 (ESI $\dagger$ ). Due to molecular symmetry the chemical shifts of $\mathrm{H} 4 / \mathrm{C} 4$ and $\mathrm{H} 5 / \mathrm{C} 5$ are respectively equivalent. For each ${ }^{1} \mathrm{H}$ and ${ }^{13} \mathrm{C}$ species of $\left[\mathrm{C}_{1} \mathrm{C}_{1} \mathrm{IM}\right]\left[\left(\mathrm{CH}_{3}\right)_{2} \mathrm{PO}_{4}\right]$ only single resonances were observed. No signals indicating impurities could be observed in the ${ }^{1} \mathrm{H}$ spectrum except a very weak water peak. The water peak intensity was in the range of ${ }^{13} \mathrm{C}$ satellite signal intensity of $\left[\mathrm{C}_{1} \mathrm{C}_{1} \mathrm{IM}\right]\left[\left(\mathrm{CH}_{3}\right)_{2} \mathrm{PO}_{4}\right]{ }^{1} \mathrm{H}$ resonances and originated from $\mathrm{H}_{2} \mathrm{O}$ traces in the used $\mathrm{D}_{2} \mathrm{O}$.

\section{NMR measurements}

All NMR experiments were acquired on Bruker AvanceIII systems with different magnetic field strengths, 9.35 $\mathrm{T}$ and 16.45 $\mathrm{T}$, corresponding to a ${ }^{13} \mathrm{C}$ resonance frequency of 100.6 $\mathrm{MHz}$ and 176.2 MHz, respectively. Both systems were equipped with $5 \mathrm{~mm}$ room-temperature liquid probes and $4 \mathrm{~mm}$ triple resonance HR-MAS probes. Liquid probe samples were fitted with a coaxial insert containing $\mathrm{D}_{2} \mathrm{O}$ for field frequency locking. All HR-MAS NMR experiments were collected without field frequency locking and the sample spin rate was $6 \mathrm{kHz}$. The field drift of both magnets was less than $0.3 \mathrm{~Hz}$ per hour without field
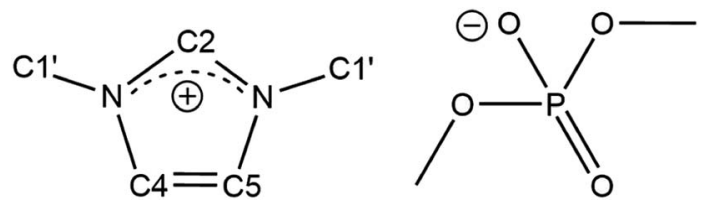

Fig. 1 Chemical structure and denotation of dimethylimidazolium dimethylphosphate $\left(\left[\mathrm{C}_{1} \mathrm{C}_{1} \mathrm{IM}\right]\left[\left(\mathrm{CH}_{3}\right)_{2} \mathrm{PO}_{4}\right]\right)$. frequency locking. The sample temperatures were controlled by variable temperature units. Temperature calibration was carried out with $4 \% \mathrm{MeOH}$ in $\mathrm{CD}_{3} \mathrm{OD}$ for the low temperature

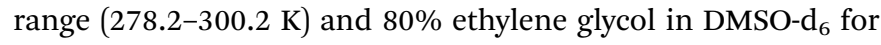
the high temperature range $(300.2-353.2 \mathrm{~K})$.

Inversion recovery experiments $\left(180^{\circ}-\tau-90^{\circ}\right)$ with power gated ${ }^{1} \mathrm{H}$ decoupling were collected and the ${ }^{13} \mathrm{C}$ longitudinal relaxation times $\left(T_{1}\right)$ were calculated from signal heights by a single exponential fit. For all experiments the relaxation delay was at least five times the longitudinal relaxation time of the slowest relaxing nucleus.

Diffusion coefficients of $\left[\mathrm{C}_{1} \mathrm{C}_{1} \mathrm{IM}\right]\left[\left(\mathrm{CH}_{3}\right)_{2} \mathrm{PO}_{4}\right]$ were measured at several temperatures using the double stimulated echo bipolar pulse-gradient pulse sequence (dstebpgp3s) for convection compensation and longitudinal eddy current delay implemented in the standard Bruker pulse library. The experimental signal amplitudes $S$ were fitted to the Stejskal-Tanner equation $^{29,30} S / S_{0}=\exp \left[-\gamma^{2} \delta^{2} g^{2}(\Delta-\delta / 3) D\right] . \gamma$ is the ${ }^{1} \mathrm{H}$ gyromagnetic ratio, $\delta$ holds the gradient pulse length, $g$ is the gradient strength, $\Delta$ reflects the diffusion time and $D_{\mathrm{t}}$ is the diffusion coefficient. $\delta$ was fixed at $3 \mathrm{~ms}$, and $\Delta$ was set appropriately. In order to avoid signal attenuation caused by the ${ }^{1} \mathrm{H} T_{1}$ relaxation timing parameters were kept constant and only the gradient strength $g$ was varied in 32 linear steps from 2 to $95 \%$ of the maximum probe gradient strength $\left(4.78 \mathrm{G} \mathrm{mm}^{-1}\right)$. The probe gradient system was calibrated by measuring the diffusion coefficient of a water sample at $298.2 \mathrm{~K}$ and compared with the literature value $\left(D_{\mathrm{t}}=2.299 \times 10^{-9} \mathrm{~m}^{2} \mathrm{~s}^{-1}\right) \cdot{ }^{31}$

Data processing was performed with Topspin 3.5.6 (Bruker Biospin $\mathrm{GmbH}$, Rheinstetten) and the relaxation data were analysed with the software Dynamics Center 2.4.4 (Bruker Biospin $\mathrm{GmbH}$, Rheinstetten).

\section{Theoretical background}

For any given system, the observed longitudinal relaxation rates are in general caused by a combination of different relaxation mechanisms and can be expressed in total according to eqn (1):

$$
R_{1}^{\mathrm{total}}=\frac{1}{T_{1}^{\mathrm{total}}}=\frac{1}{T_{1}^{\mathrm{DD}}}+\frac{1}{T_{1}^{\mathrm{CSA}}}+\frac{1}{T_{1}^{\mathrm{SR}}}+\frac{1}{T_{1}^{\mathrm{SC}}}+\frac{1}{T_{1}^{\mathrm{Q}}}
$$

Typical relaxation mechanisms for nuclear spin systems are magnetic dipole-dipole (DD) interactions, interactions by anisotropy of chemical shifts (CSA), spin-rotation (SR), scalar coupling (SC) and electric quadrupoles (Q). The potential contributions from spin-rotations, scalar couplings or electric quadrupole interactions are either absent or negligible for spin$1 / 2$ nuclei. Relaxation studies of heteronuclei, such as ${ }^{13} \mathrm{C}$, are long established and generally preferred to ${ }^{1} \mathrm{H}^{32-35}$ The relaxation properties for ${ }^{1} \mathrm{H}$ mainly depend on inter- and intramolecular dipole-dipole interactions with surrounding protons. In contrast, ${ }^{13} \mathrm{C}$ relaxation in most organic molecules usually results only from intramolecular dipolar coupling to directly attached protons. For proton-attached ${ }^{13} \mathrm{C}$ nuclei intermolecular and contributions from not directly bonded protons can be safely ignored due to the strong ${ }^{1} \mathrm{H}-{ }^{13} \mathrm{C}$ distance dependence on $r_{\mathrm{H}-\mathrm{C}}^{-6}$. 
The Bloembergen-Purcell-Pound (BPP) theory, first introduced for dipolar ${ }^{1} \mathrm{H}$ relaxation ${ }^{36}$ and later extended to other heteronuclei including ${ }^{13} \mathrm{C},{ }^{37}$ provides the theoretical basis for describing the observed $T_{1}$ temperature dependence in terms of rotational correlation time and resonance frequency. Under broadband ${ }^{1} \mathrm{H}$ decoupling and neglecting cross-correlation effects between different interactions, the dipolar longitudinal relaxation rate of proton-attached ${ }^{13} \mathrm{C}$ nuclei is given by eqn (2).

$$
\frac{1}{T_{1}^{\mathrm{DD}}}=A_{0}\left(6 J\left(\omega_{\mathrm{H}}+\omega_{\mathrm{C}}\right)+J\left(\omega_{\mathrm{H}}-\omega_{\mathrm{C}}\right)+3 J\left(\omega_{\mathrm{C}}\right)\right)
$$

$J(\omega)$ are the spectral densities with the resonance frequencies, $\omega_{\mathrm{H}}$ and $\omega_{\mathrm{C}}$, of ${ }^{1} \mathrm{H}$ and ${ }^{13} \mathrm{C}$. The constant $A_{0}$ is defined by the number $(n)$ of protons attached to ${ }^{13} \mathrm{C}$ and given in brackets, the square of the dipole-dipole coupling constant which describes the magnitude of this coupling (eqn (3)). Here, $\mu_{0}$ is the vacuum permeability, $\gamma_{\mathrm{C}}$ and $\gamma_{\mathrm{H}}$ are the magnetogyric ratios of ${ }^{13} \mathrm{C}$ and ${ }^{1} \mathrm{H}$ nuclei, $\hbar$ is the reduced Planck constant and $r_{\mathrm{CH}}$ corresponds to the length of the $\mathrm{C}-\mathrm{H}$ bond vector $(1.09 \AA) .{ }^{34}$ However, one should keep in mind that the actual $\mathrm{C}-\mathrm{H}$ bond length can be a potential source of error in the calculation of rotational correlation times. ${ }^{38}$

$$
A_{0}=\frac{n}{10}\left(\frac{\mu_{0} \gamma_{\mathrm{C}} \gamma_{\mathrm{H}} \hbar}{4 \pi r_{\mathrm{CH}}{ }^{3}}\right)^{2}
$$

In summary, $A_{0}$ is independent of temperature and frequency and takes the value of $2.15 \times 10^{9} \mathrm{~s}^{-2}$ for $n=1\left(6.45 \times 10^{9} \mathrm{~s}^{-2}\right.$ for $n=3)$.

Another source of ${ }^{13} \mathrm{C}$ relaxation is CSA. For an axiallysymmetric molecule, the principal components of the chemical shift tensor are parallel $\left(\delta_{\|}\right)$and perpendicular $\left(\delta_{\perp}\right)$ to the symmetry axis and their difference $(\Delta \delta)$ is relevant for relaxation. The longitudinal ${ }^{13} \mathrm{C}$ relaxation due to CSA is given by eqn (4).

$$
\frac{1}{T_{1}^{\mathrm{CSA}}}=\frac{2}{15} B_{0}{ }^{2} \gamma_{\mathrm{C}}{ }^{2}\left(\delta_{\|}-\delta_{\perp}\right)^{2} J\left(\omega_{\mathrm{C}}\right)
$$

For proton-attached ${ }^{13} \mathrm{C}$ nuclei with only moderately small CSA the contribution of CSA to the overall relaxation rate is one order of magnitude smaller than those for dipole-dipole relaxation and mostly neglected in the discussion of protonattached ${ }^{13} \mathrm{C}$ relaxation. However, the contribution of CSA to ${ }^{13} \mathrm{C}$ longitudinal relaxation should be taken into account in particular at high magnetic fields and in situations where the nuclei under investigation exhibits large chemical shift ranges. In such a case, the total longitudinal relaxation rate for a proton-attached ${ }^{13} \mathrm{C}$ nuclei is the sum of the rate due to dipolar interaction and CSA (eqn (5)). ${ }^{39}$

$$
\begin{aligned}
\frac{1}{T_{1}^{\text {total }}}= & A_{0}\left(6 J\left(\omega_{\mathrm{H}}+\omega_{\mathrm{C}}\right)+J\left(\omega_{\mathrm{H}}-\omega_{\mathrm{C}}\right)+3 J\left(\omega_{\mathrm{C}}\right)\right) \\
& +\left(\frac{2}{15} B_{0}^{2} \gamma_{\mathrm{C}}^{2}\left(\delta_{\|}-\delta_{\perp}\right)^{2} J\left(\omega_{\mathrm{C}}\right)\right)
\end{aligned}
$$

For rigid molecules with isotropic diffusion and a single molecular rotational correlation time $\left(\tau_{\mathrm{c}}\right)$ the spectral density $J(\omega)$ can be modelled by eqn (6):

$$
J(\omega)_{\mathrm{BPP}}=\frac{\tau_{\mathrm{c}}}{1+\left(\omega \tau_{\mathrm{c}}\right)^{2}}
$$

In situations where the ${ }^{1} \mathrm{H}_{-}{ }^{13} \mathrm{C}$ dipolar interaction (eqn (2)) is the main source of ${ }^{13} \mathrm{C}$ relaxation and the contribution of CSA is absent or not considered (second term in eqn (5) vanishes) it is worthwhile to note that eqn (2) by applying the BPP spectral density function (eqn (6)) reaches its maximum point, and hence $T_{1}$ a minimum, at $\omega_{\mathrm{C}} \tau_{\mathrm{c}}=0.791$. Using the relation $\omega_{\mathrm{H}} / \omega_{\mathrm{C}} \approx 3.98$ and rearranging eqn (2) the theoretical ${ }^{13} \mathrm{C} T_{1}$ minimum can be calculated by eqn (7):

$$
T_{1}^{\min }=\frac{\omega_{\mathrm{C}}}{1.87 A_{0}}
$$

To account for contributions from additional intramolecular motion to relaxation the generalized order parameter $S^{2}\left(0<S^{2}\right.$ $\leq 1)$ and an effective internal correlation time $\left(\tau_{\mathrm{i}}\right)$ were introduced in the "simple model-free" approach" ${ }^{\mathbf{4}}$ (eqn (8)).

$$
\begin{aligned}
J(\omega) & =S^{2}\left(\frac{\tau_{\mathrm{c}}}{1+\left(\omega \tau_{\mathrm{c}}\right)^{2}}\right)+\left(1-S^{2}\right)\left(\frac{\tau}{1+(\omega \tau)^{2}}\right) \text { and } \tau^{-1} \\
& =\tau_{\mathrm{c}}^{-1}+\tau_{\mathrm{i}}^{-1}
\end{aligned}
$$

$S^{2}$ gives a measure of the spatial restriction of intramolecular motion. An order parameter of $S^{2}=1$ implies a complete rigid internuclear vector tumbling with the overall molecular correlation time $\tau_{\mathrm{c}} . S^{2}$ would approach 0 for complete unrestricted isotropic internal motion of the bond-vector. ${ }^{39}$

For $S^{2}=1$ or in the slow intramolecular motion regime $\left(\tau_{\mathrm{i}} \gg\right.$ $\tau_{c}$ ) eqn (8) reduces to eqn (6). In the fast intramolecular motion limit $\left(\tau_{\mathrm{i}} \ll \tau_{\mathrm{c}}\right)$ eqn (8) reduces to $J(\omega)=S^{2} J(\omega)_{\mathrm{BPP}}$. One elegant way to extract information about molecular mobility from ${ }^{13} \mathrm{C}$ longitudinal relaxation times under the assumption of fast intramolecular motion and neglecting the CSA contribution is given in great detail in recent publications by Matveev et al. ${ }^{\mathbf{4 1 - 4 3}}$ With the knowledge of the precise ${ }^{13} \mathrm{C} T_{1}$ minimum it is possible to independently simplify the determination of the value of $S^{2}$ $\left(S^{2}=\omega_{\mathrm{C}} /\left(1.87 A_{0} T_{1}^{\mathrm{min}}\right)\right)$ and hence to calculate $\tau_{\mathrm{c}}$ for any given $T_{1}$.

Sometimes the relaxation of viscous liquids, even far above the melting point, is insufficiently described by eqn (6) or (8) and a correlation time distribution should be included into $J(\omega)$. For such systems the molecular motion and relaxation properties can be described more efficiently by a distribution of correlation times rather than a single correlation time and an order parameter. ${ }^{44-48}$ Therefore, the empirical Cole-Davidson (CD) approach $^{\mathbf{4 9 , 5 0}}$ (eqn (9)) is widely used in literature for quantitative analysis of relaxation data with distributed correlation times. In eqn (9) the parameter $\beta(0<\beta \leq 1)$ describes the width of the distribution and $\tau_{\mathrm{CD}}$ is related to $\tau_{\mathrm{c}}$ by $\tau_{\mathrm{c}}=\beta \tau_{\mathrm{CD}}$. For $\beta=1$ eqn (9) simplifies to eqn (6).

$$
J(\omega)_{\mathrm{CD}}=\frac{\sin \left[\beta \arctan \left(\omega \tau_{\mathrm{CD}}\right)\right]}{\omega\left[1+\left(\omega \tau_{\mathrm{CD}}\right)^{2}\right]^{\beta / 2}}
$$

Eqn (9) can also be extended by $S^{2}$ and $\tau_{\mathrm{i}}$ to accomodate additional internal motion. For fast internal motion the spectral density is given by $J(\omega)=S^{2} J(\omega)_{\mathrm{CD}}$. 
In situations where a molecule undergoes anisotropic tumbling or has moieties with fast internal reorientation compared with the overall molecular motion (e.g. fast rotating methyl groups) the order parameter $S^{2}$ can be replaced by the expression $S_{\mathrm{i}}^{2}=1 / 4\left(3 \cos ^{2}(\varphi)-1\right)^{2}$. Here, the motion of a ${ }^{13} \mathrm{C}-{ }^{1} \mathrm{H}$ vector around its rotation axis (symmetry axis) and the azimuthal angle $\varphi$ is taken into account..$^{23,35,51-54}$ For a methyl group with tetrahedral geometry $\left(\varphi=109.5^{\circ}\right) S_{\mathrm{i}}^{2}$ takes the value 0.11 . The motion of the methyl rotation axis itself is considered by setting $S^{2}=0.11 S_{\mathrm{Met}}^{2}$.

It is generally accepted that the temperature dependence of $\tau_{\mathrm{c}}$ follows the Arrhenius form (eqn (10)). $E_{\mathrm{A}}$ is the activation energy for rotational diffusion and $R$ the universal gas constant.

$$
\tau_{\mathrm{c}}=\tau_{0} \mathrm{e}^{E_{\mathrm{A}} / R T}
$$

However, sometimes eqn (10) is only applied for fast internal motion and the overall correlation time is better described by a Vogel-Fulcher-Tammann (VFT) behaviour,2,23 (eqn (11)).

$$
\tau_{\mathrm{c}}=\tau_{\mathrm{VFT}} \mathrm{e}^{E_{\mathrm{VFT}} / R\left(T-T_{0}\right)}
$$

The parameter $T_{0}$ is in the order of the glass transition temperature and $E_{\mathrm{VFT}}$ is an apparent activation energy.

The experimental relaxation data for one ${ }^{13} \mathrm{C}$ nucleus at both magnetic field strengths were simultaneously fitted with different models and parameter sets. Constrained least-square fitting was performed using Python scripts written in-house. Bounds $T_{0}>0,0<S^{2} \leq 1$ and $0<\beta \leq 1$ were imposed. The reduced $\chi^{2}$ value $\left(\chi_{\text {red }}^{2}\right)$ was used to assess the validity of the fits.

All mechanisms that contribute to ${ }^{13} \mathrm{C}$ relaxation mainly arise from intramolecular contributions. Therefore, longitudinal ${ }^{13} \mathrm{C}$ relaxation times are a reliable probe of molecular mobility and their analysis renders possible the characterization of molecular mobility in detail.

\section{Results}

\section{Comparison HR-MAS vs. liquid probe}

Most of the ${ }^{13} \mathrm{C}$ relaxation studies rely on the assumption that after inversion the recovery of the longitudinal part of the magnetisation follows a single exponential process. However, in situations where ${ }^{13} \mathrm{C}$ nuclei are directly attached to a proton, heteronuclear cross-relaxation by dipole-dipole interaction can lead to a non-exponential recovery of ${ }^{13} \mathrm{C}$ longitudinal magnetisation unless the ${ }^{13} \mathrm{C}$ spectra are collected with broadband ${ }^{1} \mathrm{H}$ decoupling. ${ }^{55}$ The impact of cross-relaxation effects on the ${ }^{13} \mathrm{C}-{ }^{1} \mathrm{H}$ dipolar relaxation mechanism was estimated by determining the ${ }^{13} \mathrm{C} T_{1}$ values under ${ }^{1} \mathrm{H}$ broadband decoupling conditions enabling NOE enhancement and under ${ }^{1} \mathrm{H}$ inverse gated decoupling without NOE enhancement at different magnetic fields and for selected temperatures (Table S1 $\dagger$ ). There are no or virtually negligible differences between the ${ }^{13} \mathrm{C} T_{1}$ values measured under broadband and gated ${ }^{1} \mathrm{H}$ decoupling at selected field strength and temperature. Based on these data we conclude that there is no impact of cross-relaxation in the ${ }^{13} \mathrm{C}-{ }^{1} \mathrm{H}$ dipoledipole relaxation mechanism neither for the $\left[\mathrm{C}_{1} \mathrm{C}_{1} \mathrm{IM}\right]^{+}$cation nor the $\left[\left(\mathrm{CH}_{3}\right)_{2} \mathrm{PO}_{4}\right]^{-}$anion within the observed temperature range. The ${ }^{13} \mathrm{C}$ relaxation by dipole-dipole interaction within $\left[\mathrm{C}_{1} \mathrm{C}_{1} \mathrm{IM}\right]$ $\left[\left(\mathrm{CH}_{3}\right)_{2} \mathrm{PO}_{4}\right]$ can be considered as a single exponential process. This is in agreement with the result presented by Imanari et al. ${ }^{\mathbf{1 9}}$ for the $\left[\mathrm{C}_{3} \mathrm{C}_{1} \mathrm{IM}\right]^{+}$cation in $\left[\mathrm{C}_{3} \mathrm{C}_{1} \mathrm{IM}\right][\mathrm{Br}]$.

To reduce residual dipolar interactions or differences in magnetic susceptibility that might be present in the sample, $\left[\mathrm{C}_{1} \mathrm{C}_{1} \mathrm{IM}\right]\left[\left(\mathrm{CH}_{3}\right)_{2} \mathrm{PO}_{4}\right]$ was also studied by HR-MAS NMR. As already shown for the high-resolution liquid probes even under magic-angle spinning there is nor difference in the ${ }^{13} \mathrm{C}$ longitudinal relaxation times determined with broadband or gated ${ }^{1} \mathrm{H}$ decoupling (Table S1 $\dagger$ ). The ${ }^{13} \mathrm{C} T_{1}$ values of single carbons obtained by collecting spectra with standard liquid probes and HR-MAS probes are highly comparable at selected field strength and temperature. On one hand this reflects the accuracy of probe temperature calibration. On the other hand the orientational components $\left(3 \cos ^{2} \theta-1\right)$ of the Hamiltonians for the dipolar interaction, CSA or differences in the magnetic susceptibility due to sample inhomogeneity are averaged to zero by molecular motion without additional sample spinning. Despite the high viscosity of $\left[\mathrm{C}_{1} \mathrm{C}_{1} \mathrm{IM}\right]\left[\left(\mathrm{CH}_{3}\right)_{2} \mathrm{PO}_{4}\right]$, the motional averaging is fast enough to remove the contributions from interactions which would lead to line broadening. This assumption is further confirmed by measuring the ${ }^{13} \mathrm{C}$ line widths at several temperatures with high-resolution liquid and HR-MAS probes with $6 \mathrm{kHz}$ sample spinning rate (Table S2†). There are no differences in the ${ }^{13} \mathrm{C}$ line widths for each carbon at selected temperatures regardless which probe was used.

All ${ }^{13} \mathrm{C}$ signals of $\left[\mathrm{C}_{1} \mathrm{C}_{1} \mathrm{IM}\right]\left[\left(\mathrm{CH}_{3}\right)_{2} \mathrm{PO}_{4}\right]$ are attenuated with decreasing temperature due to increasing line broadening, which indicates a restriction in the molecular motion. However, the methyl groups of the $\left[\mathrm{C}_{1} \mathrm{C}_{1} \mathrm{IM}\right]^{+}$cation and the $\left[\left(\mathrm{CH}_{3}\right)_{2} \mathrm{PO}_{4}\right]^{-}$ anion are less attenuated compared with the cation ring carbons. This indicates a less restricted motion of the cationic as well as the anionic methyl groups compared with cation ring carbons.

In conclusion, for $\left[\mathrm{C}_{1} \mathrm{C}_{1} \mathrm{IM}\right]\left[\left(\mathrm{CH}_{3}\right)_{2} \mathrm{PO}_{4}\right]$ a sample spinning at the "magic angle" $\left(\theta=54.7^{\circ}\right)$ is not essential to improve the spectral resolution.

\section{${ }^{13} \mathrm{C}$ relaxation studies}

The ${ }^{13} \mathrm{C}$ longitudinal relaxation times of $\left[\mathrm{C}_{1} \mathrm{C}_{1} \mathrm{IM}\right]\left[\left(\mathrm{CH}_{3}\right)_{2} \mathrm{PO}_{4}\right]$ were measured at two magnetic field strengths under broadband proton decoupling within a temperature range from 278.2 $\mathrm{K}$ to $353.2 \mathrm{~K}$ in the next step. Based on this temperature dependence and the application of different models, characteristic rotational correlation times $\left(\tau_{\mathrm{c}}\right)$ were derived for each ${ }^{13} \mathrm{C}$ nuclei in the molecule.

The temperature dependence of the ${ }^{13} \mathrm{C}$ longitudinal relaxation times is shown in Fig. 2. At first, with increasing temperature the magnitude of the ${ }^{13} \mathrm{C} T_{1}$ values decreases for all cation carbons until reaching a minimum. After passing the minimum the magnitude of the ${ }^{13} \mathrm{C} T_{1}$ values increase with increasing temperature. At a field strength of $9.35 \mathrm{~T} \mathrm{C} 2, \mathrm{C} 4 / 5$ and $\mathrm{C}^{\prime}$ of the imidazolium cation show a $T_{1}$ minimum at approx. $298 \mathrm{~K}$. For $\mathrm{C} 2$ and $\mathrm{C} 4 / 5$ the observed $T_{1}$ minima of $0.231 \mathrm{~s}$ and $0.213 \mathrm{~s}$, respectively, are close to the theoretical $T_{1}$ 
minimum of $0.158 \mathrm{~s}$ for pure dipole-dipole relaxation of a $\mathrm{CH}$ group at that field strength assuming a BPP spectral density function (eqn (7)). At $16.45 \mathrm{~T}$ the $T_{1}$ minimum of $\mathrm{C} 2, \mathrm{C} 4 / 5$ and $\mathrm{C}^{\prime}$ is uniformly shifted to $303 \mathrm{~K}$ and for $\mathrm{C} 2$ and $\mathrm{C} 4 / 5$ the values in the $T_{1}$ minimum $(0.341 \mathrm{~s}$ and $0.305 \mathrm{~s})$ closely match the calculated $T_{1}$ minimum of $0.276 \mathrm{~s}$. The fact that all $\left[\mathrm{C}_{1} \mathrm{C}_{1} \mathrm{IM}\right]^{+}$ cation ring carbons for a given magnetic field strength have a $T_{1}$ minimum at nearly the same temperature indicates an isotropic reorientation of the cation. The deviation between the measured and the calculated relaxation times can be explained by a distribution of correlation times or additional internal motion of the $\mathrm{H}-\mathrm{C}$ bond vector, which corroborates the application of "model-free" approach (eqn (8)).

At all temperatures the product of the $T_{1}$ relaxation times of the $\mathrm{C}^{\prime}$ methyl nuclei and the number of attached protons $(n=$ $3)$ is larger than those of the $\mathrm{C} 2$ and $\mathrm{C} 4 / 5 \mathrm{CH}$ groups $(n=1)$ by a factor of 9-12. The inverse of this factor is in the order of 0.1 corresponding to the aforementioned expression of $S^{2}$ for fast rotating methyl groups with tetrahedral geometry. Furthermore, the measured $\mathrm{C}^{\prime}$ relaxation times indicate an unrestrained rotational motion of the $\left[\mathrm{C}_{1} \mathrm{C}_{1} \mathrm{IM}\right]^{+}$methyl groups. The theoretical ${ }^{13} \mathrm{C} T_{1}$ values for dipole-dipole relaxation of a methyl group with free internal rotation also depend on the selected X-C-H bond angle $\varphi$. For $\varphi=109.5^{\circ}{ }^{13} \mathrm{C} T_{1}$ of a rapidly rotating $\mathrm{CH}_{3}$ group which is 3-times longer than for a $\mathrm{CH}$ moiety under the assumption that both have the same effective rotational correlation time. With an increasing bond angle $\left(\varphi>109.5^{\circ}\right)$ the longitudinal ${ }^{13} \mathrm{C}$ relaxation time of $\mathrm{CH}_{3}$ theoretically increases further by a factor of $\approx 4, \approx 4.5$ and $\approx 5$ for $\varphi$ values of $112^{\circ}$, $113^{\circ}$ and $114^{\circ}$, respectively, compared to a $\mathrm{CH}$ group. A rough estimation of the ${ }^{13} \mathrm{C} T_{1}$ ratio of $\mathrm{C}^{\prime}{ }^{\prime}$ and $\mathrm{C} 2$ or $\mathrm{C} 4 / 5$ of the $\left[\mathrm{C}_{1} \mathrm{C}_{1} \mathrm{IM}\right]^{+}$cation suggests that the bond angle $\varphi$ of the methyl group is slightly greater than $109.5^{\circ}$.

The methyl carbons in the $\left[\left(\mathrm{CH}_{3}\right)_{2} \mathrm{PO}_{4}\right]^{-}$anion only reveal a $T_{1}$ minimum at $288 \mathrm{~K}$ for a field strength of $16.45 \mathrm{~T}$, indicating a much more active motion compared with the carbons of the cation. Within the selected temperature range no $T_{1}$ minimum could be observed at $9.35 \mathrm{~T}$ for the methyl carbons of the $\left[\left(\mathrm{CH}_{3}\right)_{2} \mathrm{PO}_{4}\right]^{-}$anion. It can be assumed that the methyl carbon of the $\left[\left(\mathrm{CH}_{3}\right)_{2} \mathrm{PO}_{4}\right]^{-}$anion would also show a minimum in the ${ }^{13} \mathrm{C} T_{1}$ relaxation time at $9.35 \mathrm{~T}$, which however would appear only at a lower temperature than accessible in this study. For the
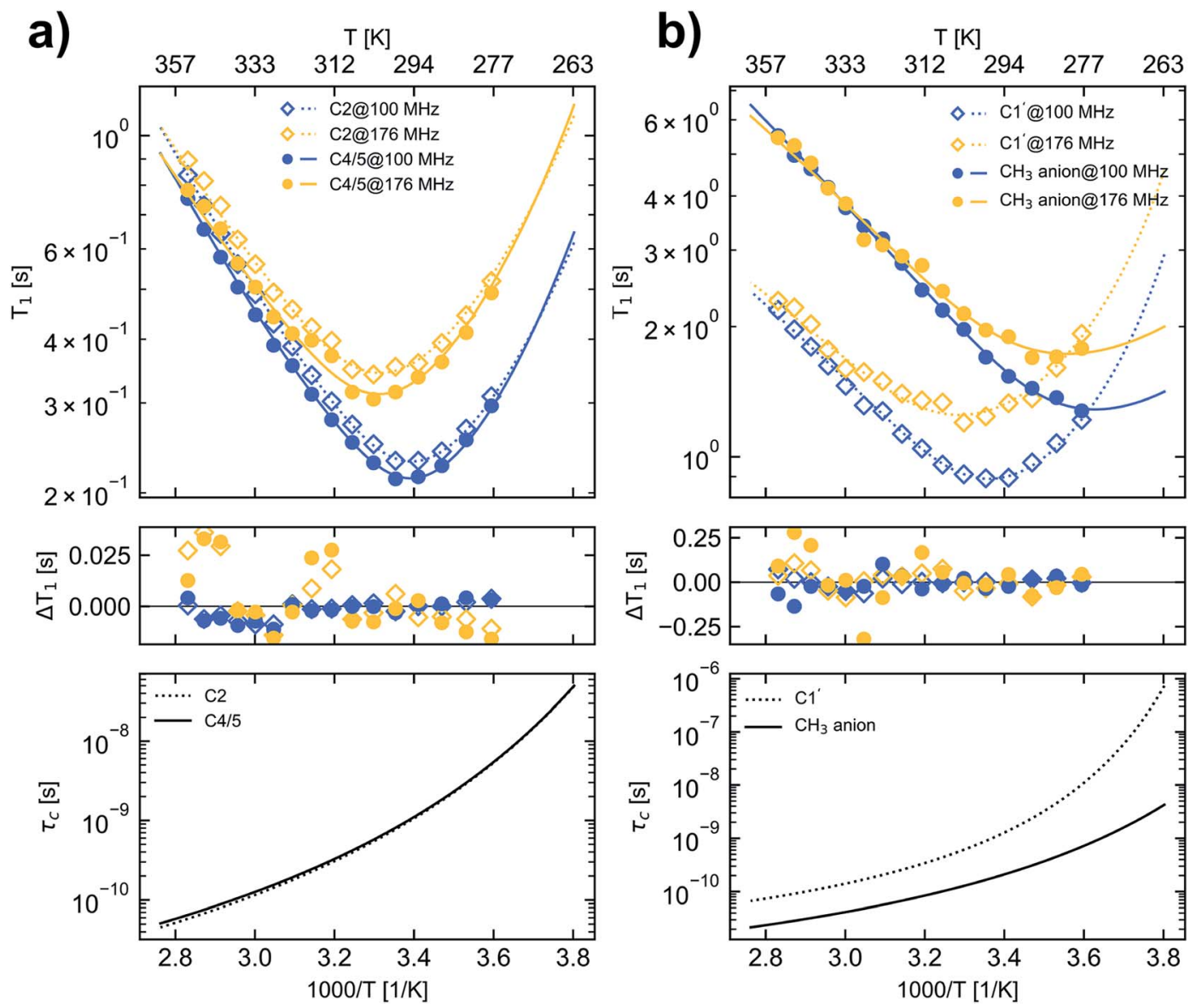

Fig. $2{ }^{13} \mathrm{C}$ longitudinal relaxation times (upper panels), the difference between measured and fitted relaxation times (middle panel) and the calculated $\tau_{\mathrm{c}}$ values (lower panel) for carbons in $\left[\mathrm{C}_{1} \mathrm{C}_{1} \mathrm{IM}\right]\left[\left(\mathrm{CH}_{3}\right)_{2} \mathrm{PO}_{4}\right]$ as a function of temperature. (a) carbon $\mathrm{C} 2$ (open squares and dotted lines) and $\mathrm{C} 4 / 5$ (filled circles and solid lines), (b) carbon $\mathrm{C1}^{\prime}$ (open squares and dotted lines) and $\mathrm{CH}_{3}$ carbons of the anion (filled circles and solid lines). For denotation see Fig. 1. Blue and yellow markers represent data measured at $B_{0}$ of $9.35 \mathrm{~T}$ and $16.45 \mathrm{~T}$ corresponding to a ${ }^{13} \mathrm{C}$ resonance frequency of $100.6 \mathrm{MHz}$ and $176.2 \mathrm{MHz}$, respectively. The lines in the upper panel represent calculated ${ }^{13} \mathrm{C}$ relaxation times according the fit parameters given in Table 2D. 
methyl carbons in the $\left[\left(\mathrm{CH}_{3}\right)_{2} \mathrm{PO}_{4}\right]^{-}$anion no clear field strength dependence of the $T_{1}$ relaxation could be observed in the high temperature range $(>320 \mathrm{~K})$. Also for the carbons of the cation the differences in the $T_{1}$ values reduce with increasing temperatures (Fig. 2, Table S3†).

\section{CSA contribution to ${ }^{13} \mathrm{C}$ relaxation}

Mostly, the relaxation of proton attached ${ }^{13} \mathrm{C}$ nuclei in the liquid state is solely discussed in terms of dipolar interaction and the contribution of CSA to relaxation is neglected in literature.

Measuring ${ }^{13} \mathrm{C} T_{1}$ relaxation times at different magnetic field strengths in the fast motion limit $\left(\omega_{C} \tau_{\mathrm{c}} \ll 1\right)$ directly allows an estimation of the CSA contribution to relaxation. From the data obtained in this study, we can not completely exclude CSA contributions to relaxation for any carbons of $\left[\mathrm{C}_{1} \mathrm{C}_{1} \mathrm{IM}\right]$ $\left[\left(\mathrm{CH}_{3}\right)_{2} \mathrm{PO}_{4}\right]$ but the comparable ${ }^{13} \mathrm{C} T_{1}$ times at different magnetic field strengths in the high temperature range indicate only a minor effect of CSA to relaxation compared to dipoledipole interaction. This is in agreement with the observation of Imanari et al. ${ }^{19}$ who stated also a minor impact of CSA for imidazolium based IL cations. However, in situations where CSA additionally contributes to ${ }^{13} \mathrm{C}$ relaxation eqn (5) should be more suitable to represent the measured ${ }^{13} \mathrm{C} T_{1}$ relaxation times. Therefore, we analysed our data in two ways: without taking account of CSA and in consideration of CSA.

\section{Calculation of $\tau_{\mathrm{c}}$ and $\boldsymbol{E}_{\mathrm{a}}$}

Considering the above remarks, at first we treated the ${ }^{13} \mathrm{C}$ relaxation times of $\left[\mathrm{C}_{1} \mathrm{C}_{1} \mathrm{IM}\right]\left[\left(\mathrm{CH}_{3}\right)_{2} \mathrm{PO}_{4}\right]$ as a result of the dipole-dipole relaxation mechanism between carbons and directly attached protons which can be described readily by eqn (2) and the modified BPP spectral density function (eqn (8)). We assume that the intramolecular motion is at least one order of magnitude faster than the overall molecular motion $\left(\tau_{i} \ll \tau_{\mathrm{c}}\right)$ so that the second term in eqn (8) is negligible. For comparison the CD spectral density (eqn (9)) was also used for fitting. The temperature dependence of $\tau_{\mathrm{c}}$ was modelled with the Arrhenius (eqn (10)) and VFT (eqn (11)) approach, respectively. In the Arrhenius approach one activation energy is assumed for the entire temperature range. However, for viscous liquids a decreasing temperature can correlate with an increasing activation energy. Such a behaviour is sometimes better described by the VFT equation. ${ }^{2,23}$ For $\left[\mathrm{C}_{1} \mathrm{C}_{1} \mathrm{IM}\right]\left[\left(\mathrm{CH}_{3}\right)_{2} \mathrm{PO}_{4}\right]$ the precise glass transition temperature is not known but it was experimentally shown that for imidazolium based ILs the glass transition temperature is in the range of $180-220 \mathrm{~K} \cdot{ }^{56-61}$ The fit parameters are summarized in Table 1.

Regardless of the type of spectral density function or temperature dependence which is applied, all fits provide comparable results with respect to the order parameter, activation energy and rotational correlation time. Even the obtained $T_{0}$ parameters are in agreement with values reported in literature. There is no difference in the goodness-of-fit between the application of the Arrhenius or the VFT approximation for the temperature dependence of $\tau_{\mathrm{c}}$. The same applies for the used spectral density functions. However no reliable fit could be obtained for the methyl carbon of the anion by applying the VFT approach for the $\tau_{\mathrm{c}}$ temperature dependence. It has to be noted that the application of the Arrhenius approach provides very good fits for the methyl carbon of the anion. The experimental data at $9.35 \mathrm{~T}$ are obviously better represented by the fit parameters than the relaxation data at $16.45 \mathrm{~T}$ potentially indicating a more pronounced CSA contribution at the higher field strength.

In the next step we treated the ${ }^{13} \mathrm{C}$ relaxation as a combination of dipole-dipole interaction and CSA (eqn (5)) under the assumption of fast internal motion. Again the experimental data were fitted to a BPP (eqn (8)) and CD (eqn (9)) type spectral density function and the Arrhenius (eqn (10)) and VFT (eqn (11)) approach for the temperature dependence of $\tau_{\mathrm{c}}$, respectively. The obtained fit parameters are compiled in Table 2. Taking account of CSA significantly improves the goodness-of-fit and the experimental data at both magnetic field strengths are well represented by the fit parameters. The estimated $\Delta \delta$ values for the IL ring carbons are in the range of 112-142 ppm. This is in agreement with $\Delta \delta$ for aromatic ring carbons reported by others. ${ }^{23,62,63}$ However, the fitted $\Delta \delta$ values (Table 2) for the methyl carbons are unexpectedly high when the motion of the ${ }^{13} \mathrm{C}-{ }^{1} \mathrm{H}$ vector around its rotation axis is considered $\left(S^{2}=\right.$ $0.11 S_{\mathrm{Met}}^{2}$ ). Excluding the factor 0.11 during fitting would result in $\Delta \delta$ values in the range of 40-60 ppm for the methyl carbons.

The calculated $\tau_{c}$, for example at $298 \mathrm{~K}$, are nearly equal within the selected spectral density approach for all carbons of the $\left[\mathrm{C}_{1} \mathrm{C}_{1} \mathrm{IM}\right]^{+}$cation characterizing a uniform reorientation and molecular mobility. Moreover, our ${ }^{13} \mathrm{C}$ relaxation measurements at two different magnetic field strengths reveal nearly the same rotational correlation times for all cation carbons (Tables 1 and 2) regardless of the selected type of spectral density function or approach for the temperature dependence of $\tau_{\mathrm{c}}$. Under this point of view the assumption of isotropic motion for the imidazolium ring is justified at least at room temperature. The activation energies $\left(E_{A}\right)$ of molecular reorientation for the imidazolium ring carbons are in the range of $32-38 \mathrm{~kJ} \mathrm{~mol}^{-1}$ for BPP type spectral density and $39-42 \mathrm{~kJ} \mathrm{~mol}^{-1}$ for $\mathrm{CD}$ approach, respectively. Using VFT approach to model the temperature dependence of $\tau_{\mathrm{c}}$ results in activation energies $\left(E_{\mathrm{VFT}}\right)$ within $2-8 \mathrm{~kJ} \mathrm{~mol}^{-1}$. These values are consistent with results obtained by others for imidazolium ring carbons and attached methyl groups. ${ }^{19,23,41,42,64}$ The fitted $E_{\mathrm{A}} / E_{\mathrm{VFT}}$ values are nearly unaffected by the inclusion of CSA to the analysis of the relaxation data. Only the combination of BPP spectral density function, including the CSA relaxation mechanism and a VFT type $\tau_{\mathrm{c}}$ temperature dependency results in high $E_{\mathrm{VFT}}$ values of $17-23 \mathrm{~kJ} \mathrm{~mol}^{-1}$ and low $T_{0}$ values for the $\left[\mathrm{C}_{1} \mathrm{C}_{1} \mathrm{IM}\right]^{+}$ carbons (Table 2C).

It was shown recently that the behaviour of the anion as a whole can be reasonably described by values obtained for methyl groups in carbon containing IL anions. ${ }^{43,64}$ For the methyl carbons of the anion, the calculated activation energies $\left(E_{\mathrm{A}} / E_{\mathrm{VFT}}\right)$ are considerably lower compared with cation carbons. At $298 \mathrm{~K} \tau_{\mathrm{c}}$ is at least three to five times shorter than the corresponding values of the cation indicating a faster reorientation mobility of the anion. Moreover, this emphasises the hypothesis that cation and anion behave independently as dissociated ions 
Table 1 Fit parameter values for the ${ }^{13} \mathrm{C}$ relaxation expressed by eqn (2). The spectral density functions given in eqn (8) (A, C) and eqn (9) (B, D) were used for fitting. The temperature dependence of $\tau_{C}$ was fitted with eqn (10) (A, B) and eqn (11) (C, D), respectively

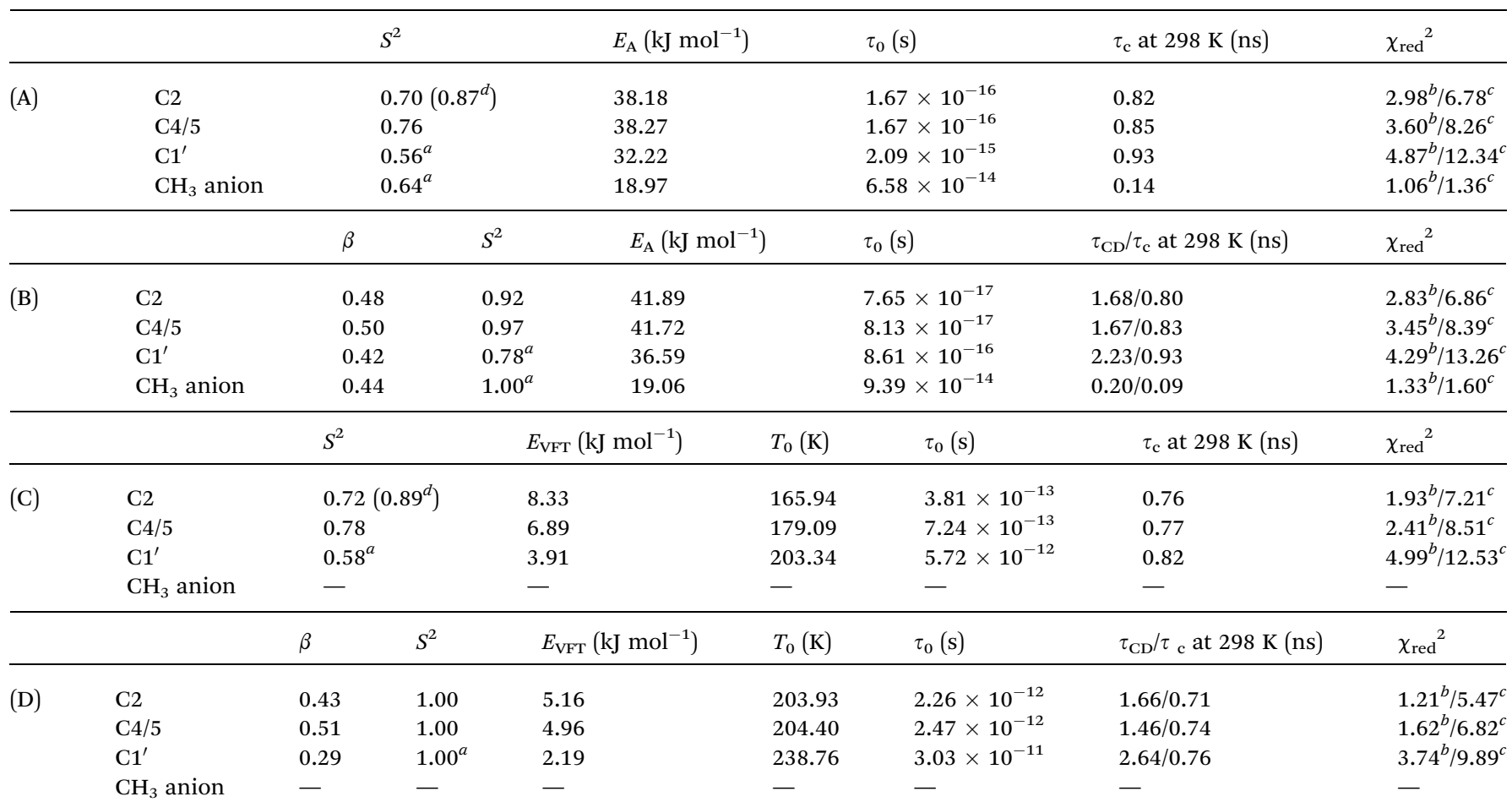

${ }^{a}$ Fast methyl-group rotation was considered by modifying $S^{2}$ with the factor $0.11\left(S^{2}=0.11 S_{\text {Met }}{ }^{2}\right)$. For methyl carbons $S_{\text {Met }}{ }^{2}$ is given. ${ }^{b}$ Reduced $\chi^{2}$ values for data at $9.35 \mathrm{~T}^{c}{ }^{c}$ Reduced $\chi^{2}$ values for data at $16.45 \mathrm{~T}$. ${ }^{d}$ Fitted $S^{2}$ with a C-H bond length of $1.13 \AA$.

and may form rather short-living ion pairs. We wish to point out that the molecular mobilities of $\left[\mathrm{C}_{1} \mathrm{C}_{1} \mathrm{IM}\right]^{+}$and $\left[\left(\mathrm{CH}_{3}\right)_{2} \mathrm{PO}_{4}\right]^{-}$ should be considered as time-weighted averages between the reorientation dynamics of tightly associated $\left[\mathrm{C}_{1} \mathrm{C}_{1} \mathrm{IM}\right]-$ $\left[\left(\mathrm{CH}_{3}\right)_{2} \mathrm{PO}_{4}\right]$ ion pairs and single dissociated ions.

The $\mathrm{S}^{2}$ of the ring carbons $\mathrm{C} 2(\approx 0.6-0.72)$ and $\mathrm{C} 4 / 5(\approx 0.64-$ $0.78)$ calculated under the assumption of a $\mathrm{C}-\mathrm{H}$ bond length of $1.09 \AA$ and a BPP type spectral density would reveal a moderate degree of additional internal motion. The slightly lower $S^{2}$ of C2 compared to $\mathrm{C} 4 / 5$ suggests accordingly that the proton attached to $\mathrm{C} 2$ is not preferentially involved in $\mathrm{H}$-bonding in comparison to the other ring protons. The participation of the cationic $\mathrm{H} 2$ in hydrogen bonding with anions should result in a more constrained orientation, and hence higher order parameter of the corresponding $\mathrm{C}-\mathrm{H}$ vector. The prominent role of the $\mathrm{C} 2$ position of imidazolium based IL cations in interacting with anions mainly via hydrogen bonding is extensively described in literature..$^{18,23,65-71}$ It is well known that the length of a C-H bond can vary depending on the hybridization of the carbon atom and the polarity of the bond..$^{72}$ In this context, Antony et al..$^{73}$ postulated for the strong hydrogen bonding donor at position $\mathrm{C} 2$ of the imidazolium based cation (in this case 1-butyl-3methylimidazolium) a C-H bond length of $1.13 \AA$ A Reevaluating the $\mathrm{C} 2$ data with an elongated $\mathrm{C}-\mathrm{H}$ bond length results in higher $S^{2}$ values. By applying a C-H bond length of $1.13 \AA S^{2}$ of C2 increases to values up to 0.99 . These higher order parameters would corroborate the hypothesis that the proton in $\mathrm{C} 2$ position acts in hydrogen bond formation with the anion also for $\left[\mathrm{C}_{1} \mathrm{C}_{1} \mathrm{IM}\right]\left[\left(\mathrm{CH}_{3}\right)_{2} \mathrm{PO}_{4}\right]$. The $\mathrm{H}$-bond formation mainly between the $\mathrm{CH}$ group in position 2 of the cation and the $\left[\left(\mathrm{CH}_{3}\right)_{2} \mathrm{PO}_{4}\right]^{-}$anion is in agreement with existing hypothesis about the cationic-anionic interaction in imidazolium based ILs and the ability of $\left[\left(\mathrm{CH}_{3}\right)_{2} \mathrm{PO}_{4}\right]^{-}$to act as relatively strong $\mathrm{H}-$ bond acceptor. ${ }^{71}$ The order parameters obtained for the methyl groups in $\mathrm{C}^{\prime}$ and the anion are slightly smaller compared to the ring carbons when the BPP type spectral density is applied for fitting. This indicates a slightly higher flexibility of the methyl carbons.

With respect to $S^{2}$ the results are somewhat different when the CD spectral density function is used. Here, the best fits were obtained when the fit parameter $S^{2}$ takes rather high values which would correlate with no or only very limited internal motion. However, the low $\beta$ values of all carbons in $\left[\mathrm{C}_{1} \mathrm{C}_{1} \mathrm{IM}\right]\left[\left(\mathrm{CH}_{3}\right)_{2} \mathrm{PO}_{4}\right]$ could point to a broad distribution of correlation times.

The consistency between the fit parameters and the data derived at two magnetic field strengths justifies the chosen theoretical models and the approach of evaluation. The combination of applying the CD type spectral density function, the VFT approach for the $\tau_{\mathrm{c}}$ temperature dependence and taking CSA into account provides the best fit results for our experimental data within the selected temperature range (Fig. 2). Experimental data at lower temperatures or higher magnetic field strengths than accessible in this study would further improve the reliability of the proposed fitting approach mainly 
Table 2 Fit parameter values for the ${ }^{13} \mathrm{C}$ relaxation expressed by eqn (5). The spectral density functions given in eqn (8) (A, C) and eqn (9) (B, D) were used for fitting. The temperature dependence of $\tau_{c}$ was fitted with eqn (10) and (11), respectively

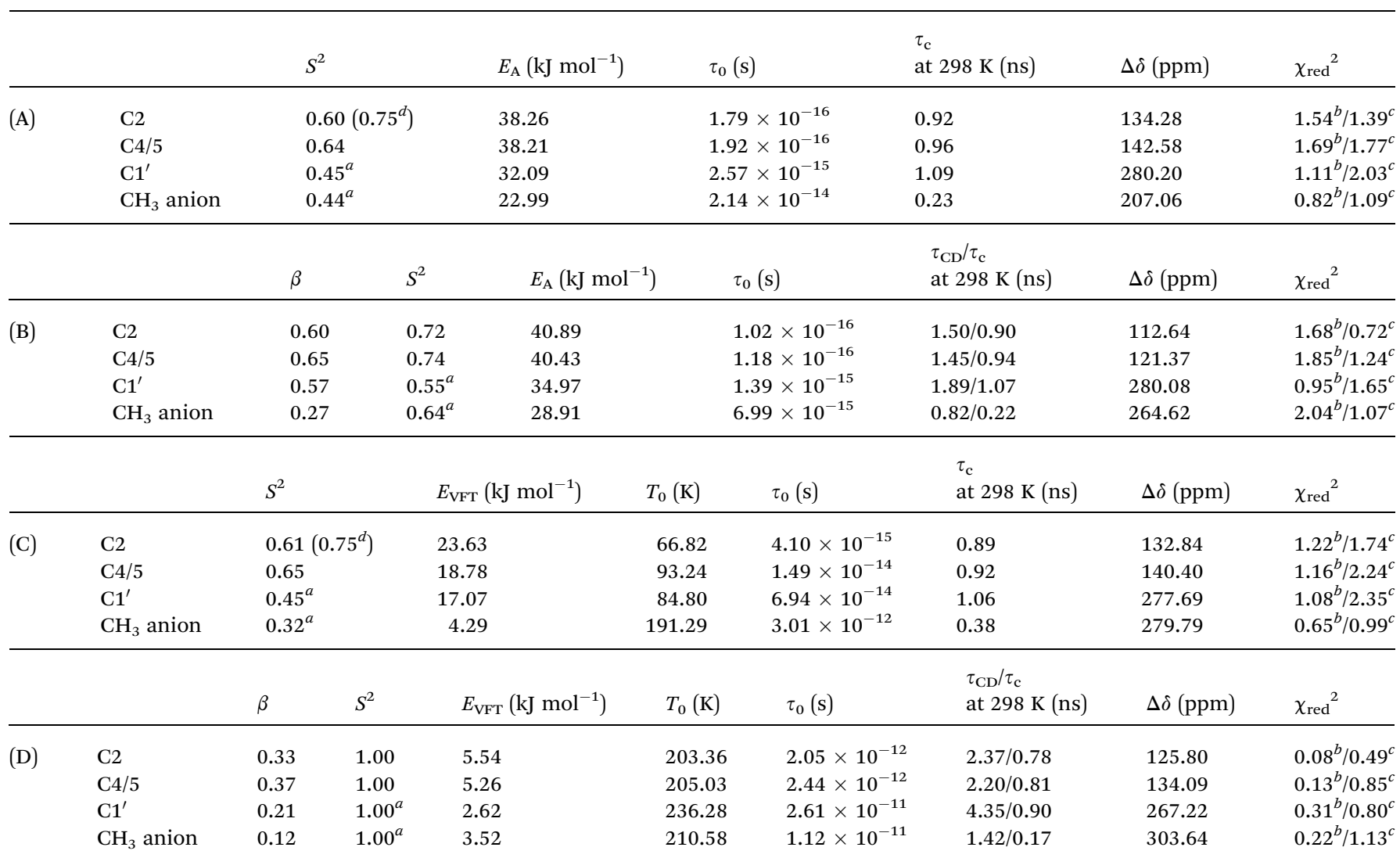

${ }^{a}$ Fast methyl-group rotation was considered by modifying $S^{2}$ with the factor $0.11\left(S^{2}=0.11 S_{\text {Met }}{ }^{2}\right)$. For methyl carbons $S_{\text {Met }}{ }^{2}$ is given. ${ }^{b}$ Reduced $\chi^{2}$ values for data at $9.35 \mathrm{~T}^{c}{ }^{c}$ Reduced $\chi^{2}$ values for data at $16.45 \mathrm{~T} .{ }^{d}$ Fitted $S^{2}$ with a C-H bond length of $1.13 \AA$.

for the more mobile IL anion. However, we do not want to conceal that our experimental data are also considerably well represented by the simple assumption of dipolar relaxation and the BPP spectral density function including $S^{2}$ only (Table 1A).

As already mentioned (see Theoretical background) in situations where the temperature dependence of the ${ }^{13} \mathrm{C} T_{1}$ values reveals a precise minimum the independent calculation of $S^{2}$ $\left(S^{2}=\omega_{\mathrm{C}} /\left(1.87 A_{0} T_{1}^{\mathrm{min}}\right)\right)$ and thus $\tau_{\mathrm{c}}$ for any given $T_{1}$ is possible. For further information we refer to the recent publications by Matveev et al. ${ }^{\mathbf{4 1 , 4 2 , 6 4}}$ Since the ${ }^{13} \mathrm{C}$ nuclei in $\left[\mathrm{C}_{1} \mathrm{C}_{1} \mathrm{IM}\right]\left[\left(\mathrm{CH}_{3}\right)_{2} \mathrm{PO}_{4}\right]$ reveal $T_{1}$ minima, we also calculated $S^{2}$ and extracted $\tau_{\mathrm{c}}$ values for each temperature for comparison as proposed by the authors. Finally the $\tau_{\mathrm{c}}$ temperature dependence was fitted according the Arrhenius (eqn (10)) and VFT approach (eqn (11)). The motional characteristics of $\left[\mathrm{C}_{1} \mathrm{C}_{1} \mathrm{IM}\right]\left[\left(\mathrm{CH}_{3}\right)_{2} \mathrm{PO}_{4}\right]$ applying this approach are summarized in Table $\mathrm{S} 4$ and depicted in Fig. S3 and S4.† Particularly with respect to $S^{2}, \tau_{\mathrm{c}}$ and $E_{\mathrm{A}}$ the fit parameters obtained by applying the BPP spectral density function and neglecting any CSA contributions are in remarkable agreement with the values obtained by simultaneous fitting the relaxation data of two magnetic field strengths (Tables 1 and 2). In conclusion, if a clear temperature dependent ${ }^{13} \mathrm{C} T_{1}$ minimum is observable at one magnetic field strength, the calculation of $S^{2}$ in that point, and thereafter $\tau_{\mathrm{c}}$ and $E_{\mathrm{A}}$, provides a robust and reliable approach for the extraction of information about molecular motion.

\section{Nuclear Overhauser effect}

The nuclear Overhauser effect (NOE) is an import consequence of dipolar relaxation. In addition, to validate that the ${ }^{13} \mathrm{C}$ relaxation proceeds mainly by dipole-dipole interaction with attached protons the NOE enhancement factors $\eta$ were measured in addition for selected temperatures, field strengths and probe settings (Table S5† and Fig. 3). Depending on the selected field strength comparable enhancement factors were obtained for each temperature using either HR-MAS or liquid probes.

The maximum $\eta$ observable relies on the rotational correlation time and thus on the molecular motion of the nuclei under investigation. Other relaxation pathways than intramolecular dipole-dipole interaction, which contribute to the longitudinal relaxation rate (e.g. CSA or intermolecular dipole-dipole interaction), can reduce the maximum $\eta$ (eqn (12)). ${ }^{39}$ Here we examine the ${ }^{13} \mathrm{C}$ NOE enhancement taking CSA into account. In the case that CSA is not considered the term $\left(\Delta \delta=\delta_{\|}-\delta_{\perp}\right)$ in eqn (12) is set to 0 . 


$$
\eta_{\max }=\frac{\gamma_{\mathrm{H}}}{\gamma_{\mathrm{C}}} \frac{\left(6 J\left(\omega_{\mathrm{H}}+\omega_{\mathrm{C}}\right)-J\left(\omega_{\mathrm{H}}-\omega_{\mathrm{C}}\right)\right)}{\left(6 J\left(\omega_{\mathrm{H}}+\omega_{\mathrm{C}}\right)+J\left(\omega_{\mathrm{H}}-\omega_{\mathrm{C}}\right)+3 J\left(\omega_{\mathrm{C}}\right)\right)+\left(\frac{2}{15} B_{0}{ }^{2} \gamma_{\mathrm{C}}{ }^{2}\left(\delta_{\|}-\delta_{\perp}\right)^{2} J\left(\omega_{\mathrm{C}}\right)\right)}
$$

On the basis of the best parameters derived from fitting the relaxation data (Table $2 \mathrm{D}, \mathrm{CD}$ type spectral density function and CSA contribution) the dependence of $\eta_{\max }$ on $\tau_{\mathrm{c}}$ was calculated and depicted in Fig. 3. For comparison also the $\eta_{\max }$ dependence on $\tau_{\mathrm{c}}$ was calculated using the fit parameter given in Tables 1A and D (see Fig. S5 and S6 $\dagger$ ). Because for the selected temperatures $(278.2 \mathrm{~K}, 293.2 \mathrm{~K}$ and $323.2 \mathrm{~K})$ the molecular motion of $\left[\mathrm{C}_{1} \mathrm{C}_{1} \mathrm{IM}\right]\left[\left(\mathrm{CH}_{3}\right)_{2} \mathrm{PO}_{4}\right]$ is not in the fast motion limit $\left(\omega_{\mathrm{C}} \tau_{\mathrm{c}} \ll 1\right)$ and the relaxation by CSA is considered as a leakage term the maximum $\eta$ observable of 1.98 for pure ${ }^{1} \mathrm{H}-{ }^{13} \mathrm{C}$ dipolar interaction can not be reached.

However, an increase in temperature resulting in shorter $\tau_{\mathrm{c}}$ correlates with increased $\eta$ values as shown in Fig. 3. For carbon $\mathrm{C} 2$ and $\mathrm{C} 4 / 5$ the observed enhancement factors $\eta$ match the theoretical ones reasonably well and higher enhancements are obtained in the motion regime of $\omega_{C} \tau_{\mathrm{c}} \approx 1$ at $9.35 \mathrm{~T}$ compared with 16.45 T. For the methyl carbons the observed enhancement factors deviate substantially from the expected values. The
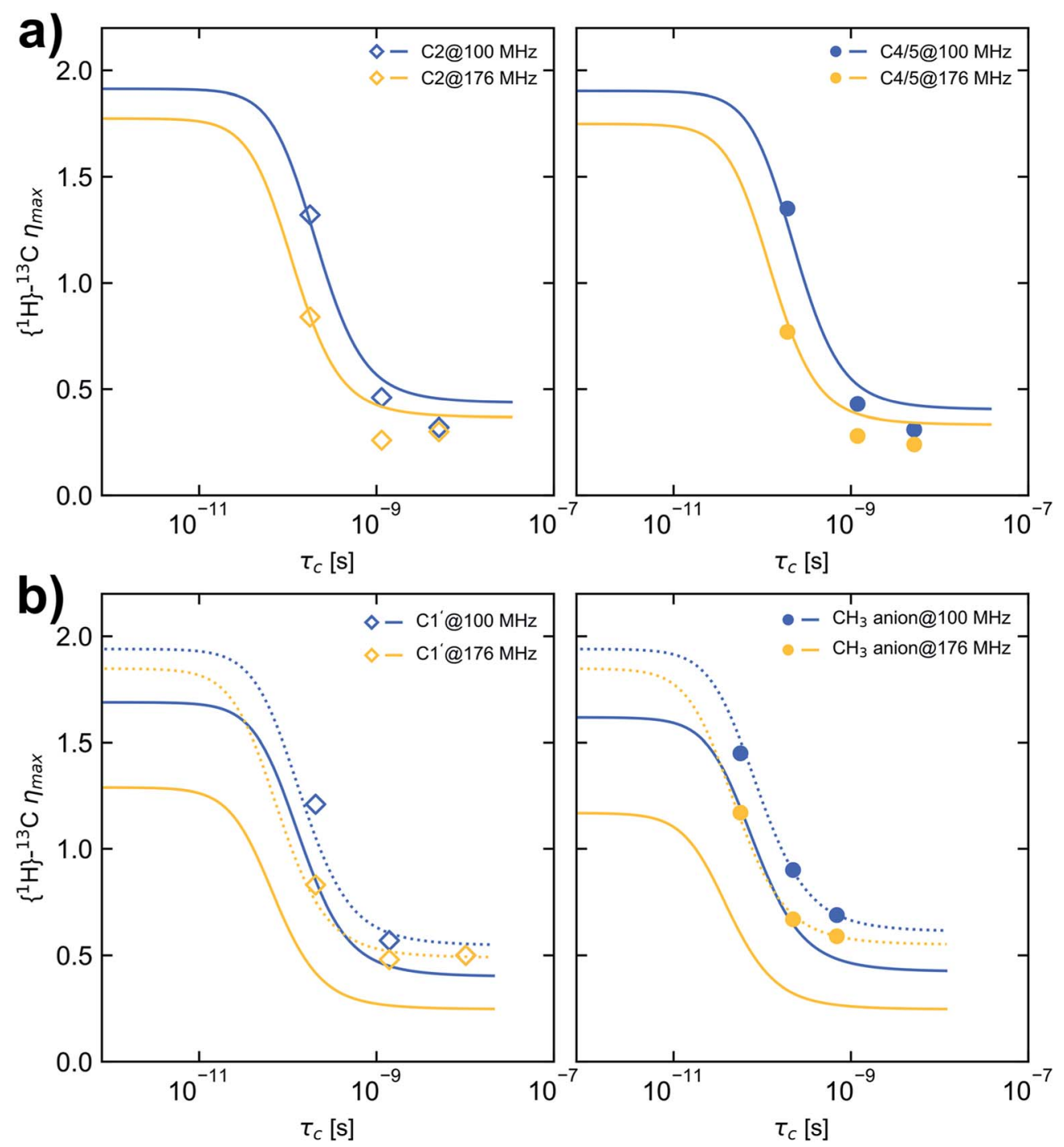

Fig. 3 Dependence of maximum $\left\{{ }^{1} \mathrm{H}\right\}-{ }^{13} \mathrm{C}$ NOE enhancement $\left(\eta_{\max }\right)$ on $\tau_{\mathrm{c}}$ calculated for a CD spectral density function and considering CSA with the fit parameters given in Table 2D (solid lines). (a) carbon C2 (left, open squares) and C4/5 (right, filled circles), (b) carbon C1' (left, open squares) and $\mathrm{CH}_{3}$ carbon of the anion (right, filled circles). Dashed lines in (b) are calculated with the fit parameters given in Table 2D but a CSA value of $100 \mathrm{ppm}$. Blue and yellow markers represent data measured at $B_{0}$ of $9.35 \mathrm{~T}$ and $16.45 \mathrm{~T}$ corresponding to a ${ }^{13} \mathrm{C}$ resonance frequency of 100.6 $\mathrm{MHz}$ and 176.2 $\mathrm{MHz}$, respectively. 
reason could be that the $\Delta \delta$ values for the methyl groups ( $\Delta \delta=$ 267 and $303 \mathrm{ppm}$, respectively) are overestimated in the fitting procedure. Recalculating the dependence of $\eta_{\max }$ on $\tau_{\mathrm{c}}$ with a $\Delta \delta$ value of $100 \mathrm{ppm}$ reveal a nearly perfect agreement between measured and expected NOE enhancement factors (Fig. 3b, dashed lines). This confirms that the $\mathrm{CD}$ spectral density function and fitted parameters $\beta, E_{\mathrm{VFT}}, T_{0}$ and $\tau_{0}$ at least are suitable to model the molecular mobility of $\left[\mathrm{C}_{1} \mathrm{C}_{1} \mathrm{IM}\right]$ $\left[\left(\mathrm{CH}_{3}\right)_{2} \mathrm{PO}_{4}\right]$. From fitting the relaxation data and comparing the measured and calculated $\eta$ values the ${ }^{13} \mathrm{C}$ relaxation of $\left[\mathrm{C}_{1} \mathrm{C}_{1} \mathrm{IM}\right]$ $\left[\left(\mathrm{CH}_{3}\right)_{2} \mathrm{PO}_{4}\right]$ partially by CSA can't be excluded. Moreover, for $\Delta \delta$ $\approx 100 \mathrm{ppm}$ the maximum relaxation rate due to CSA is $0.4 \mathrm{~s}^{-1}$ (at 9.35 T) and $0.7 \mathrm{~s}^{-1}$ (at 16.45 T). CSA contributes field strength dependent to the overall ${ }^{13} \mathrm{C}$ relaxation $(6 \%$ and $17 \%$ at $9.35 \mathrm{~T}$ and $16.45 \mathrm{~T}$, respectively) which is nevertheless dominantly driven by dipolar ${ }^{1} \mathrm{H}^{-13} \mathrm{C}$ relaxation. However, the absolute $\Delta \delta$ values, mainly for the methyl groups, needs to be taken with caution and it has to be mentioned that the CSA magnitude can vary with temperature. Additional relaxation data at other magnetic field strengths or the direct measurement of the CSA is necessary to verify the fitted $\Delta \delta$ values.

\section{Diffusion study}

To gain a deeper understanding of cation-anion association/ dissociation, formation of ion pairs or the aggregation of ions is of vital interest not only in the description of the IL electrical conductance and mass transport but also to rationalise the individual interaction of cation and anion with potential solute molecules.

Each of the four well resolved resonances in the ${ }^{1} \mathrm{H}$ spectrum of $\left[\mathrm{C}_{1} \mathrm{C}_{1} \mathrm{IM}\right]\left[\left(\mathrm{CH}_{3}\right)_{2} \mathrm{PO}_{4}\right]$ has been used to determine the temperature dependence of the translational self-diffusion coefficients $\left(D_{\mathrm{t}}\right)$. Three out of the four resonances were assigned to the $\left[\mathrm{C}_{1} \mathrm{C}_{1} \mathrm{IM}\right]^{+}$cation and the $D$ values obtained for the cation are averaged (see Table S6 $\dagger$ ). The temperature dependence of $D$ is shown in Fig. 4a and fitted to an Arrhenius-type equation (eqn (10)). The activation energies of translational diffusion, $E_{\mathrm{A}}$, for the neat $\left[\mathrm{C}_{1} \mathrm{C}_{1} \mathrm{IM}\right]\left[\left(\mathrm{CH}_{3}\right)_{2} \mathrm{PO}_{4}\right]$ are $36.5 \pm 1.9 \mathrm{~kJ} \mathrm{~mol}^{-1}$ and $35.8 \pm$ $2.2 \mathrm{~kJ} \mathrm{~mol}^{-1}$ for the $\left[\mathrm{C}_{1} \mathrm{C}_{1} \mathrm{IM}\right]^{+}$cation and the $\left[\left(\mathrm{CH}_{3}\right)_{2} \mathrm{PO}_{4}\right]^{-}$anion, respectively. These values are in the same order found for other ILs. ${ }^{59-61,74-76}$ It is interesting that $E_{\mathrm{A}}$ for diffusion and rotational correlation give nearly the same values at least for the cation. The activation energy of the anion for diffusion is slightly higher compared to the rotational correlation.

The increase in the diffusion coefficients for both cation and anion with increasing temperature is to be expected. The diffusion coefficients associated with the $\left[\mathrm{C}_{1} \mathrm{C}_{1} \mathrm{IM}\right]^{+}$cation are higher than the values obtained for the $\left[\left(\mathrm{CH}_{3}\right)_{2} \mathrm{PO}_{4}\right]^{-}$for the whole temperature range. The apparent cationic transference number and the predicted molar conductivity derived from the self-diffusion coefficients of $\left[\mathrm{C}_{1} \mathrm{C}_{1} \mathrm{IM}\right]\left[\left(\mathrm{CH}_{3}\right)_{2} \mathrm{PO}_{4}\right]$ are calculated and plotted in Fig. S7. $\dagger$ In contrast to other imidazolium based ILs ${ }^{59-61}$ here, we observe an increase in the apparent cationic transference number with increasing temperature (Fig. S7a†). This can be rationalised by the slightly lower activation energy for the diffusion of the anion compared to the cation. At higher temperatures the diffusion of $\left[\left(\mathrm{CH}_{3}\right)_{2} \mathrm{PO}_{4}\right]^{-}$increases relatively less compared to the IL cation. The high cationic transference numbers of $\left[\mathrm{C}_{1} \mathrm{C}_{1} \mathrm{IM}\right]\left[\left(\mathrm{CH}_{3}\right)_{2} \mathrm{PO}_{4}\right]$ also reveal a faster diffusion of the cation than the anion, even though both ions are similar in size, and that the difference in cationic and anionic diffusion increases with temperature.

As already reported in earlier studies on several imidazolium $^{59-61,74,75}$ or piperidinium ${ }^{76}$ based ILs also in our investigation the anion diffuses at a slower rate than the cation. In most of these previous reports the slower diffusing anion was smaller compared to a larger IL cation. The primary aggregation of IL anions resulting in a lower anionic diffusion constant was proposed to rationalise this surprising observation on the one hand. ${ }^{74,77}$ On the other hand it was suggested that the diffusion of the IL cation is faster than expected. ${ }^{75}$

According to the Stokes-Einstein equation (eqn (13)) the selfdiffusion coefficient is inversely proportional to hydrodynamic radius $(r)$ and, therefore, to the volume $(V)$ of a spherical particle under investigation. ${ }^{78}$ For considering the anion and the cation it follow the ratios: ${ }^{3} \sqrt{ } V_{\text {cation }} / \sqrt{3} \sqrt{\text { anion }}=r_{\text {cation }} / r_{\text {anion }}=D_{\text {anion }} /$ $D_{\text {cation. }}$. The calculated van-der-Waals volumes ${ }^{79}$ (and effective radiii $\left.{ }^{7480}\right)$ of the $\left[\mathrm{C}_{1} \mathrm{C}_{1} \mathrm{IM}\right]^{+}$cation and the $\left[\left(\mathrm{CH}_{3}\right)_{2} \mathrm{PO}_{4}\right]^{-}$anion are $89.8 \AA^{3}(2.59 \AA)$ and $96.8 \AA^{3}(2.82 \AA)$, respectively, and, hence, result in a theoretical ratio of the diffusion coefficients of $D_{\text {anion }} /$ $D_{\text {cation }}=0.97$ and hydrodynamic radii of $r_{\text {cation }} / r_{\text {anion }}=0.92$ for $\left[\mathrm{C}_{1} \mathrm{C}_{1} \mathrm{IM}\right]\left[\left(\mathrm{CH}_{3}\right)_{2} \mathrm{PO}_{4}\right]$. The experimental ratio $D_{\text {anion }} / D_{\text {cation }}$ continuously decreases from 0.95 at $278.2 \mathrm{~K}$ to 0.67 at $353.2 \mathrm{~K}$. At lower temperatures the experimental $D_{\text {anion }} / D_{\text {cation }}$ is in total agreement with the theoretical ratio and the lower $D_{\text {anion }}$ can be explained by the larger anionic volume. However, at higher temperatures the experimental $D_{\text {anion }} / D_{\text {cation }}$ deviates clearly from the theoretical ratio.

$$
D_{\mathrm{t}}=\frac{k_{\mathrm{B}} T}{6 c \pi \eta r}
$$

In order to clarify the disparity the hydrodynamic radii of $\left[\mathrm{C}_{1} \mathrm{C}_{1} \mathrm{IM}\right]^{+}$and $\left[\left(\mathrm{CH}_{3}\right)_{2} \mathrm{PO}_{4}\right]^{-}$were evaluated on the basis of the experimental data. The Stokes-Einstein relationship (eqn (13)), where $k_{\mathrm{B}}$ and $T$ correspond to Boltzmann constant and the temperature, models the self-diffusion coefficient $\left(D_{\mathrm{t}}\right)$ for a sphere of an effective hydrodynamic radius $(r)$ with the temperature depenent viscosity $(\eta)$ of a solution. Here, $c$ is a constant that depends on the hydrodynamic particle-fluid boundary conditions. Assuming infinite dilution of a large diffusing sphere compared to the surrounding solvent the constant $c=1$ (stick boundary conditions). In situations where solute and solvent are of similar size (slip boundary conditions) or intermolecular interaction, non-spherical shape or aggregation need to be considered in the adjustment of the constant $c$ was proposed..$^{18,74,80-82}$ In our analysis the value $2 / 3$ is applied for the constant $c$.

In a classical description the rotational correlation time $\tau_{\mathrm{c}}$ of an isotropically diffusing sphere is given by eqn (14)..$^{18,78,81,82}$ The combination of eqn (13) and (14) by eliminating $\eta, k_{\mathrm{B}}$ and $T$ makes it possible to correlate both NMR accessible values $D_{\mathrm{t}}$ and $\tau_{\mathrm{c}}$ to the hydrodynamic radius $r$ of a particle under 

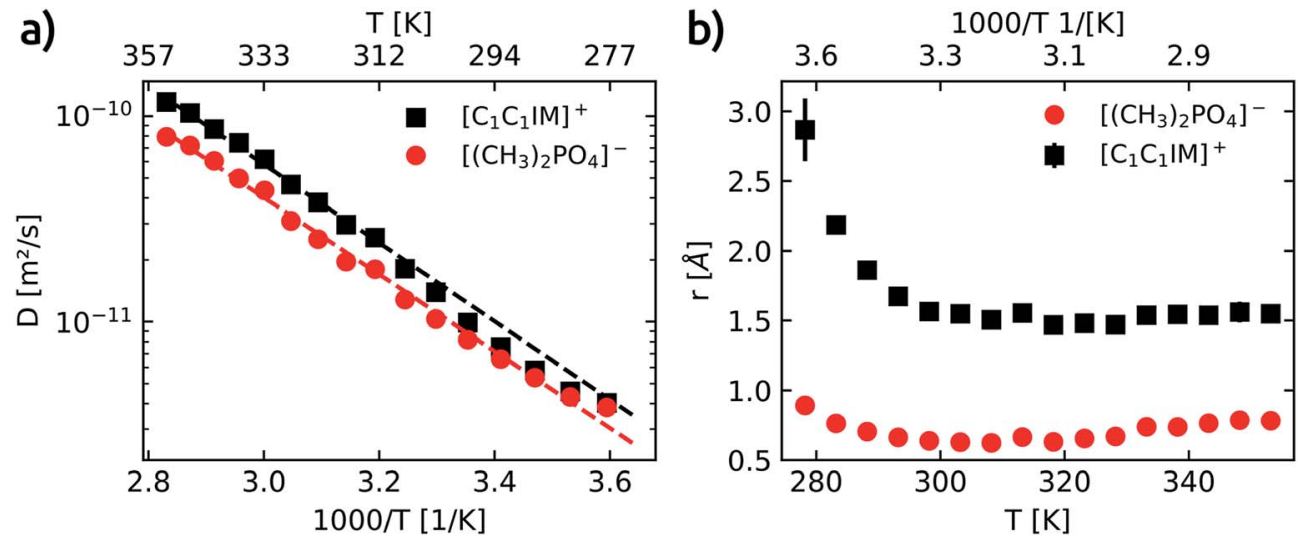

Fig. 4 (a) Temperature dependence of the self-diffusion coefficients (D) for the $\left[\mathrm{C}_{1} \mathrm{C}_{1} I \mathrm{M}\right]^{+}$cation (black squares) and the $\left[\left(\mathrm{CH}_{3}\right)_{2} \mathrm{PO} \mathrm{O}_{4}\right]^{-}$anion $(\mathrm{red}$ circles). Dashed lines show fits for $\left[\mathrm{C}_{1} \mathrm{C}_{1} \mathrm{IM}\right]^{+}$(black) and $\left[\left(\mathrm{CH}_{3}\right)_{2} \mathrm{PO} 4\right]^{-}$(red) calculated with the Arrhenius equation $D=D_{0} \exp \left(-E_{\mathrm{A}} / R T\right)$. $D_{0}$ is a fitting constant, $E_{\mathrm{a}}$ gives the activation energy for self-diffusion, $R$ is the universal gas constant and $T$ is the temperature. (b) Calculated effective hydrodynamic radii $(r)$ of $\left[\mathrm{C}_{1} \mathrm{C}_{1} \mathrm{IM}\right]^{+}$(black squares) and $\left[\left(\mathrm{CH}_{3}\right)_{2} \mathrm{PO}_{4}\right]^{-}$(red circles) as a function of temperature.

investigation (eqn (15)). Applying the fit parameters from Table $2 \mathrm{D}$ allowed the calculation of $\tau_{\mathrm{c}}$ for every temperature.

$$
\begin{gathered}
\tau_{\mathrm{c}}=\frac{\eta 4 \pi r^{3}}{3 k_{\mathrm{B}} T} \\
r=\sqrt{D_{\mathrm{t}} \tau_{\mathrm{c}} 9 / 2 c}
\end{gathered}
$$

Based on eqn (15) the hydrodynamic radii of the $\left[\mathrm{C}_{1} \mathrm{C}_{1} \mathrm{IM}\right]^{+}$ cation and $\left[\left(\mathrm{CH}_{3}\right)_{2} \mathrm{PO}_{4}\right]^{-}$anion were calculated and presented in Fig. $4 \mathrm{~b}$ as a function of temperature. The hydrodynamic radius of the anion slightly decrease in the temperature range between 278-293 $\mathrm{K}$ and is then nearly constant for the temperature range studied. In contrast the hydrodynamic radius of the cation significantly reduces with increasing temperature up to $293 \mathrm{~K}$ and then reaches a constant value at higher temperatures. The simultaneous decrease in the hydrodynamic radii of both the cation and the anion between 278-293 K suggests the formation of cationic-anion pairs. However, it is reasonable to draw the conclusion that no long existing cation-anion ion pairs are formed in the temperature range above $293 \mathrm{~K}$. Averaged over the temperature range above $293 \mathrm{~K}$ the hydrodynamic radii of the $\left[\mathrm{C}_{1} \mathrm{C}_{1} \mathrm{IM}\right]^{+}$cation and the $\left[\left(\mathrm{CH}_{3}\right)_{2} \mathrm{PO}_{4}\right]^{-}$anion are $1.73 \pm 0.06 \AA$ and $0.71 \pm 0.07 \AA$, respectively. By setting the constant $c$ to 1 the obtained hydrodynamic radii are slightly larger $\left(\left[\mathrm{C}_{1} \mathrm{C}_{1} \mathrm{IM}\right]^{+}: r=\right.$ $\left.1.87 \pm 0.04 \AA,\left[\left(\mathrm{CH}_{3}\right)_{2} \mathrm{PO}_{4}\right]^{-}: r=0.87 \pm 0.09 \AA\right)$. In addition, the ${ }^{13} \mathrm{C}$ correlation times were plotted versus the inverse of the diffusion coefficient (see Fig. S8†). The slopes also provide information about $r$. The hydrodynamic radii of $\left[\mathrm{C}_{1} \mathrm{C}_{1} \mathrm{IM}\right]^{+}$and $\left[\left(\mathrm{CH}_{3}\right)_{2} \mathrm{PO}_{4}\right]^{-}$obtained from this correlation are $1.64 \pm 0.03 \AA$ $(2.00 \pm 0.03 \AA$ for $c=1)$ and $0.72 \pm 0.02 \AA(0.88 \pm 0.02 \AA$ for $c=$ 1), respectively. Huang et al. correctly point out the limitations (isotropic reorientation of a spherical-top) of hydrodynamic radii derived from reorientation dynamics. ${ }^{68}$ Nevertheless, for small and symmetric particles the applied theory is appropriate.

The experimentally acquired $r$ of the cation is slightly smaller than theoretically estimated but in good agreement with other results for imidazolium based IL cations. ${ }^{\mathbf{6 8 , 7 4 , 8 2 , 8 3}}$ Within limits, this corroborates the Stokes-Einstein approximation made and shows the applicability of eqn (15) for estimating hydrodynamic radii based on $\tau_{\mathrm{c}}$ and $D$ at least for the imidazolium based IL cation.

However, the experimentally based radius of the anion seems to be unrealistic small and deviates significantly from the theoretical value. If the aforementioned consideration $\left(r_{\text {cation }} /\right.$ $r_{\text {anion }}=D_{\text {anion }} / D_{\text {cation }}$ ) holds true, one should expect nearly the same value for both ratios. The experimental ratio of the hydrodynamic radii $r_{\text {cation }} / r_{\text {anion }}$ is in the range of 1.98-2.52 and reveals a clear contradiction to the experimentally obtained ratio of the diffusion coefficients $D_{\text {anion }} / D_{\text {cation }}=0.76$ averaged over the temperature range.

Assuming the radius of the anion derived from rotational correlation times, and hence, the ratio $r_{\text {cation }} / r_{\text {anion }}=1.98-2.52$, is correct, this would imply that the measured diffusion coefficients of the $\left[\left(\mathrm{CH}_{3}\right)_{2} \mathrm{PO}_{4}\right]^{-}$anion are too small by a factor of $\approx 2.6-3.3$. However, it is more likely that the calculated radius of the anion based on eqn (15) is too small. Under the premise that the calculated $\tau_{\mathrm{c}}$ values of the anion are correct and that the actual hydrodynamic radius of a single and isolated $\left[\left(\mathrm{CH}_{3}\right)_{2} \mathrm{PO}_{4}\right]^{-}$particle has nearly the same value as the cation ( $\approx 2 \AA$, s. above) the measured diffusion coefficients of the anion are too small by a factor of $\approx 4$ to 6 for this molecular size and $\tau_{\mathrm{c}}$ values. In reverse, if it means that in average 4-6 $\left[\left(\mathrm{CH}_{3}\right)_{2} \mathrm{PO}_{4}\right]^{-}$anions cluster, is subject to speculation. The $\left[\left(\mathrm{CH}_{3}\right)_{2} \mathrm{PO}_{4}\right]^{-}$anion diffuse substantially slower than expected, in particular in the high temperature range. To explain these phenomena the concept of anion-rich aggregates in ILs was recently suggested and experimentally verified. ${ }^{74,77}$ Along this line, the diffusion coefficients and, thus, the derived hydrodynamic radii of $\left[\mathrm{C}_{1} \mathrm{C}_{1} \mathrm{IM}\right]^{+}$and $\left[\left(\mathrm{CH}_{3}\right)_{2} \mathrm{PO}_{4}\right]^{-}$and their interpretation presented in this study render the formation of anionic aggregates a suitable model to explain the comparatively low diffusion coefficients of the anion. One should keep in mind the different NMR time scales at which the diffusion ( $\mathrm{ms}$ to $\mathrm{s}$ ) and the reorientation (ns) dynamics are studied. Both time scales are too long for the detection of short-living uncharged IL ion 
pairs. The lifetime of such ion pairs was estimated to be in $\geq \mathrm{ps}$ time frame. ${ }^{18}$ The longitudinal ${ }^{13} \mathrm{C}$ relaxation of $\left[\mathrm{C}_{1} \mathrm{C}_{1} \mathrm{IM}\right]$ $\left[\left(\mathrm{CH}_{3}\right)_{2} \mathrm{PO}_{4}\right]$ may reflects the rotational reorientation of single/ not aggregated ionic particles in the ns time regime whereas the diffusion represents a "longtime" averaged clustering/ aggregation mainly of the anions. Based on our NMR data presented here no reliable statement about the number of clustering anions is possible. The concept of cooperative hydrogen bonding was introduced to rationalise the cationic aggregates. ${ }^{\mathbf{8 4} 85}$ The question needs to be resolved how anionic aggregates can overcome the repulsive Coulomb interaction.

\section{Conclusion}

Here, we report about the analysis of reorientation mobility of the room temperature IL $\left[\mathrm{C}_{1} \mathrm{C}_{1} \mathrm{IM}\right]\left[\left(\mathrm{CH}_{3}\right)_{2} \mathrm{PO}_{4}\right]$ on the basis of ${ }^{13} \mathrm{C}$ longitudinal relaxation times measured at two magnetic field strengths by means of standard NMR liquid probes and by applying magic angle spinning. In addition, an analysis of the diffusion coefficients measured by PFG-NMR techniques at temperatures ranging from $278 \mathrm{~K}$ to $353 \mathrm{~K}$ was performed to correlate the rotational correlation times and the diffusion coefficients with the hydrodynamic radii of the $\left[\mathrm{C}_{1} \mathrm{C}_{1} \mathrm{IM}\right]^{+}$cation and the $\left[\left(\mathrm{CH}_{3}\right)_{2} \mathrm{PO}_{4}\right]^{-}$anion.

Despite their high viscosity pure imidazolium based ILs with a melting point at ambient temperatures can be properly studied by standard liquid NMR probe heads. With respect to IL signal line width, and hence resolution no improvement could be obtained by applying HR-MAS probes.

Therefore, the ${ }^{13} \mathrm{C}$ longitudinal relaxation behaviour of the $\left[\mathrm{C}_{1} \mathrm{C}_{1} \mathrm{IM}\right]^{+}$cation as well as the $\left[\left(\mathrm{CH}_{3}\right)_{2} \mathrm{PO}_{4}\right]^{-}$anion within the tested temperature range is reliably described by the BPP theory, the application of the generalised order parameter and an Arrhenius type $\tau_{\mathrm{c}}$ temperature dependence. However, with regard to the goodness-of-fit ( $\chi_{\text {red }}{ }^{2}$ in Tables 1 and 2 ) the ${ }^{13} \mathrm{C}$ longitudinal relaxation behaviour is more precisely represented by the application of the CD type spectral density function, VFT type $\tau_{\mathrm{c}}$ temperature dependence and the consideration of CSA to ${ }^{13} \mathrm{C}$ relaxation. This agrees with the findings from others. ${ }^{23,47}$ Additional relaxation data at a wider range of magnet field strengths and/or temperatures would be necessary to corroborate the distinction between different dynamic models and the total amount of CSA contribution. In this respect, it has to be mentioned that field-cycling NMR relaxometry is a valuable technique to obtain information on molecular dynamics over a broad range of Larmor frequencies ( $\mathrm{kHz}$ to $\mathrm{MHz}) .{ }^{48,86}$ We wish to point out that field-cycling NMR relaxometry is successfully employed to investigate the dynamics of ILs recently. ${ }^{26,45,47,63,87-92}$

Although from a theoretical point of view similar in size, the $\left[\mathrm{C}_{1} \mathrm{C}_{1} \mathrm{IM}\right]^{+}$cation and the $\left[\left(\mathrm{CH}_{3}\right)_{2} \mathrm{PO}_{4}\right]^{-}$anion reveal different reorientation mobilities and diffusivities. The $\left[\left(\mathrm{CH}_{3}\right)_{2} \mathrm{PO}_{4}\right]^{-}$anion shows a three to five times faster reorientation at room temperature compared to the cation. This indicates that cation and anion are not tightly associated in their reorientation mobility.

The temperature dependence of the self-diffusion coefficients is sufficiently described by the Arrhenius equation in the selected temperature range. In the course of the diffusion measurements we did not observe any indications of phase separation, and hence structural heterogeneity. It can be speculated that at lower temperatures the translational diffusion don't follow an Arrhenius-type but rather a VFT-type thermally activated process, as already observed for ILs. ${ }^{47,93}$ Intriguingly, the activation energies derived from relaxation data and diffusion measurements are nearly the same at least for the cation. This suggests that the effective size of the $\left[\mathrm{C}_{1} \mathrm{C}_{1} \mathrm{IM}\right]^{+}$cation is the same for rotational correlation and diffusion. For the $\left[\mathrm{C}_{1} \mathrm{C}_{1} \mathrm{IM}\right]^{+}$cation the hydrodynamic radius derived from rotational correlation times and diffusion coefficients fits very well with theoretical considerations and imply the existence of single dissociated cationic particles.

Assuming that the hydrodynamic radius of an isolated $\left[\left(\mathrm{CH}_{3}\right)_{2} \mathrm{PO}_{4}\right]^{-}$anion is similar to the $\left[\mathrm{C}_{1} \mathrm{C}_{1} \mathrm{IM}\right]^{+}$cation the measured diffusion coefficients of the anion are too small to corroborate the model of single diffusing anionic entities. In contrast, the $\left[\left(\mathrm{CH}_{3}\right)_{2} \mathrm{PO}_{4}\right]^{-}$anion diffuses slower than expected and reveals a diffusion behaviour that indicates the formation of anionic aggregates.

Mainly with respect to IL ions interacting with solute molecules a better understanding of the ionic aggregation state and the dissociated action of IL cation and anion will help to rationalise the effects observed.

It has to be proven further whether and by which way of action the presence of solute molecules (in addition to carbohydrates e.g. peptides or proteins) in pure ILs has a measurable impact on the IL microstructure.

\section{Conflicts of interest}

There are no conflicts to declare.

\section{Acknowledgements}

The authors would like to thank Prof. T. Michael Duncan at Cornell University for his support. Support by the "Institut für Technische Biochemie (ITB) e.V." affiliated at the Martin Luther University Halle-Wittenberg is gratefully acknowledged. In addition, we acknowledge the financial support of the Martin Luther University Halle-Wittenberg within the funding programme Open Access Publishing by the German Research Foundation (DFG).

\section{References}

$1 \mathrm{~J}$. P. Hallett and T. Welton, Room-Temperature Ionic Liquids: Solvents for Synthesis and Catalysis. 2, Chem. Rev., 2011, 111, 3508-3576.

$2 \mathrm{H}$. Weingärtner, Understanding Ionic Liquids at the Molecular Level: Facts, Problems, and Controversies, Angew. Chem., Int. Ed., 2008, 47, 654-670.

3 R. Hayes, G. G. Warr and R. Atkin, Structure and Nanostructure in Ionic Liquids, Chem. Rev., 2015, 115, 6357-6426.

4 M. Watanabe, M. L. Thomas, S. Zhang, K. Ueno, T. Yasuda and K. Dokko, Application of Ionic Liquids to Energy 
Storage and Conversion Materials and Devices, Chem. Rev., 2017, 117, 7190-7239.

5 C. Dai, J. Zhang, C. Huang and Z. Lei, Ionic Liquids in Selective Oxidation: Catalysts and Solvents, Chem. Rev., 2017, 117, 6929-6983.

6 Z. Zhang, J. Song and B. Han, Catalytic Transformation of Lignocellulose into Chemicals and Fuel Products in Ionic Liquids, Chem. Rev., 2017, 117, 6834-6880.

7 N. Wehofsky, C. Wespe, V. Cerovsky, A. Pech, E. Hoess, R. Rudolph and F. Bordusa, Ionic Liquids and Proteases: A Clean Alliance for Semisynthesis, ChemBioChem, 2008, 9, 1493-1499.

8 Y. Fukaya, K. Hayashi, M. Wada and H. Ohno, Cellulose dissolution with polar ionic liquids under mild conditions: required factors for anions, Green Chem., 2008, 10, 44-46.

9 D. Diddens, V. Lesch, A. Heuer and J. Smiatek, Aqueous ionic liquids and their influence on peptide conformations: Denaturation and dehydration mechanisms, Phys. Chem. Chem. Phys., 2017, 19, 20430-20440.

10 H. Weingärtner, C. Cabrele and C. Herrmann, How ionic liquids can help to stabilize native proteins, Phys. Chem. Chem. Phys., 2012, 14, 415-426.

11 M. Silva, A. M. Figueiredo and E. J. Cabrita, Epitope mapping of imidazolium cations in ionic liquid-protein interactions unveils the balance between hydrophobicity and electrostatics towards protein destabilisation, Phys. Chem. Chem. Phys., 2014, 16, 23394-23403.

12 T. Takekiyo and Y. Yoshimura, Suppression and dissolution of amyloid aggregates using ionic liquids, Biophys. Rev., 2018, 10, 853-860.

13 K. Damodaran, in Annual Reports on NMR Spectroscopy, Elsevier Ltd., 1st edn, 2016, vol. 88, pp. 215-244.

14 R. Nanda and K. Damodaran, A review of NMR methods used in the study of the structure and dynamics of ionic liquids, Magn. Reson. Chem., 2018, 56, 62-72.

15 Y. Lingscheid, S. Arenz and R. Giernoth, Heteronuclear NOE Spectroscopy of Ionic Liquids, ChemPhysChem, 2012, 13, 261-266.

16 R. Giernoth, D. Bankmann and N. Schlörer, High performance NMR in ionic liquids, Green Chem., 2005, 7, 279.

17 D. Bankmann and R. Giernoth, Magnetic resonance spectroscopy in ionic liquids, Prog. Nucl. Magn. Reson. Spectrosc., 2007, 51, 63-90.

18 H. Weingärtner, NMR studies of ionic liquids: Structure and dynamics, Curr. Opin. Colloid Interface Sci., 2013, 18, 183189.

19 M. Imanari, H. Tsuchiya, H. Seki, K. Nishikawa and M. Tashiro, Characterization of the molecular reorientational dynamics of the neat ionic liquid 1-butyl-3methylimidazolium bromide in the super cooled state using ${ }^{1} \mathrm{H}$ and ${ }^{13} \mathrm{C}$ NMR spectroscopy, Magn. Reson. Chem., 2009, 47, 67-70.

20 W. R. Carper, P. G. Wahlbeck, J. H. Antony, D. Mertens, A. Dölle and P. Wasserscheid, A Bloembergen-PurcellPound 13C NMR relaxation study of the ionic liquid 1- butyl-3-methylimidazolium hexafluorophosphate, Anal. Bioanal. Chem., 2004, 378, 1548-1554.

21 N. E. Heimer, J. S. Wilkes, P. G. Wahlbeck and W. R. Carper, ${ }^{13} \mathrm{C}$ NMR relaxation rates in the ionic liquid 1-ethyl-3methylimidazolium butanesulfonate, J. Phys. Chem. A, 2006, 110, 868-874.

22 J. H. Antony, A. Dölle, D. Mertens, P. Wasserscheid, W. R. Carper and P. G. Wahlbeck, ${ }^{13} \mathrm{C}$ NMR relaxation rates in the ionic liquid 1-methyl-3-nonylimidazolium hexafluorophosphate, J. Phys. Chem. A, 2005, 109, 66766682.

23 J. H. Antony, D. Mertens, A. Dölle, P. Wasserscheid and W. R. Carper, Molecular reorientational dynamics of the neat ionic liquid 1-butyl-3-methylimidazolium hexafluorophosphate by measurement of ${ }^{13} \mathrm{C}$ nuclear magnetic relaxation data, ChemPhysChem, 2003, 4, 588-594.

24 P. G. Gordon, D. H. Brouwer and J. A. Ripmeester, Probing the Local Structure of Pure Ionic Liquid Salts with Solidand Liquid-State NMR, ChemPhysChem, 2010, 11, 260-268.

25 F. Cesare Marincola, C. Piras, O. Russina, L. Gontrani, G. Saba and A. Lai, NMR investigation of imidazoliumbased ionic liquids and their aqueous mixtures, ChemPhysChem, 2012, 13, 1339-1346.

26 A. Ordikhani Seyedlar, S. Stapf and C. Mattea, Dynamics of the ionic liquid 1-butyl-3-methylimidazolium bis(trifluoromethylsulphonyl)imide studied by nuclear magnetic resonance dispersion and diffusion, Phys. Chem. Chem. Phys., 2015, 17, 1653-1659.

27 T. Endo, M. Imanari, H. Seki and K. Nishikawa, Effects of Methylation at Position 2 of Cation Ring on Rotational Dynamics of Imidazolium-Based Ionic Liquids Investigated by NMR Spectroscopy: [C4mim]Br vs [C4C1mim]Br, J. Phys. Chem. A, 2011, 115, 2999-3005.

28 T. Endo, H. Murata, M. Imanari, N. Mizushima, H. Seki, S. Sen and K. Nishikawa, A comparative study of the rotational dynamics of $\mathrm{PF}$ 6- anions in the crystals and liquid states of 1-butyl-3-methylimidazolium hexafluorophosphate: Results from ${ }^{31} \mathrm{P}$ NMR spectroscopy, J. Phys. Chem. B, 2013, 117, 326-332.

29 E. O. Stejskal and J. E. Tanner, Spin Diffusion Measurements: Spin Echoes in the Presence of a Time-Dependent Field Gradient, J. Chem. Phys., 1965, 42, 288-292.

30 J. E. Tanner, Use of the Stimulated Echo in NMR Diffusion Studies, J. Chem. Phys., 1970, 52, 2523-2526.

31 M. Holz, S. R. Heil and A. Sacco, Temperature-dependent self-diffusion coefficients of water and six selected molecular liquids for calibration in accurate ${ }^{1} \mathrm{H}$ NMR PFG measurements, Phys. Chem. Chem. Phys., 2000, 2, 4740-4742.

32 G. C. Levy, Carbon-13-spin-lattice relaxation studies and their application to organic chemical problems, Acc. Chem. Res., 1973, 6, 161-169.

33 H. W. Spiess, D. Schweitzer and U. Haeberlen, Molecular motion in liquid toluene from a study of ${ }^{13} \mathrm{C}$ and $2 \mathrm{D}$ relaxation times, J. Magn. Reson., 1973, 9, 444-460. 
34 E. Breitmaier, K.-H. Spohn and S. Berger, ${ }^{13} \mathrm{C}$ Spin-Lattice Relaxation Times and the Mobility of Organic Molecules in Solution, Angew. Chem., Int. Ed. Engl., 1975, 14, 144-159.

35 N. Platzer, Carbon ${ }^{13}$ NMR. The analysis of the relaxation times $T_{1}$ of benzofuran and of a series of its methyl derivatives. Correlations between molecular motions and structural properties, Org. Magn. Reson., 1978, 11, 350-356.

36 N. Bloembergen, E. M. Purcell and R. V. Pound, Relaxation effects in nuclear magnetic resonance absorption, Phys. Rev., 1948, 73, 679-712.

37 I. Solomon, Relaxation Processes in a System of Two Spins, Phys. Rev., 1955, 99, 559-565.

38 K. Dill and A. Allerhand, Small errors in carbon-hydrogen bond lengths may cause large errors in rotational correlation times determined from carbon-13 spin-lattice relaxation measurements, J. Am. Chem. Soc., 1979, 101, 4376-4378.

39 P. Luginbühl and K. Wüthrich, Semi-classical nuclear spin relaxation theory revisited for use with biological macromolecules, Prog. Nucl. Magn. Reson. Spectrosc., 2002, 40, 199-247.

40 G. Lipari and A. Szabo, Model-Free Approach to the Interpretation of Nuclear Magnetic Resonance Relaxation in Macromolecules. 1. Theory and Range of Validity, J. Am. Chem. Soc., 1982, 104, 4546-4559.

41 V. V. Matveev, D. A. Markelov, E. A. Brui, V. I. Chizhik, P. Ingman and E. Lähderanta, ${ }^{13} \mathrm{C}$ NMR relaxation and reorientation dynamics in imidazolium-based ionic liquids: revising interpretation, Phys. Chem. Chem. Phys, 2014, 16, 10480-10484.

42 V. V. Matveev and K. V. Tyutyukin, in Modern Problems of Molecular Physics, ed. L. A. Bulavin and A. V. Chalyi, Springer International Publishing AG, 2018, pp. 51-66.

43 V. V. Matveev, D. A. Markelov, A. V. Ievlev, E. A. Brui, K. V. Tyutyukin and E. Lähderanta, Molecular mobility in several imidazolium-based ionic liquids according to data of ${ }^{1} \mathrm{H}$ and ${ }^{13} \mathrm{C}$ NMR relaxation, Magn. Reson. Chem., 2018, 56, 140-143.

44 N. Petzold, B. Schmidtke, R. Kahlau, D. Bock, R. Meier, B. Micko, D. Kruk and E. A. Rössler, Evolution of the dynamic susceptibility in molecular glass formers: Results from light scattering, dielectric spectroscopy, and NMR, $J$. Chem. Phys., 2013, 138, 12A510.

45 M. Flämig, M. Hofmann, A. Lichtinger and E. A. Rössler, Application of proton field-cycling NMR relaxometry for studying translational diffusion in simple liquids and polymer melts, Magn. Reson. Chem., 2019, 57, 805-817.

46 W. R. Carper, Z. Meng, P. Wasserscheid and A. Dölle, NMR Relaxation Studies and Molecular Modeling of 1-butyl-3methylimidazolium PF6[BMIM][PF6], Electrochem. Soc. Proc., 2002, 2002-19, 973-982.

47 M. Wencka, T. Apih, R. C. Korošec, J. Jenczyk, M. Jarek, K. Szutkowski, S. Jurga and J. Dolinšek, Molecular dynamics of 1-ethyl-3-methylimidazolium triflate ionic liquid studied by ${ }^{1} \mathrm{H}$ and ${ }^{19} \mathrm{~F}$ nuclear magnetic resonances, Phys. Chem. Chem. Phys., 2017, 19, 15368-15376.
48 D. Kruk, A. Herrmann and E. A. Rössler, Field-cycling NMR relaxometry of viscous liquids and polymers, Prog. Nucl. Magn. Reson. Spectrosc., 2012, 63, 33-64.

49 D. W. Davidson and R. H. Cole, Dielectric Relaxation in Glycerol, Propylene Glycol, and n-Propanol, J. Chem. Phys., 1951, 19, 1484-1490.

50 P. A. Beckmann, Spectral densities and nuclear spin relaxation in solids, Phys. Rep., 1988, 171, 85-128.

51 D. E. Woessner, Nuclear Spin-Lattice Relaxation in Axially Symmetric Ellipsoids with Internal Motion, J. Chem. Phys., 1969, 50, 719.

52 J. W. Blunt and J. B. Stothers, The influence of methyl group geometry on methyl rotational barriers as estimated from ${ }^{13}$ C relaxation data, J. Magn. Reson., 1977, 27, 515-519.

53 S. Ng, R. V Sathasivam, K.-M. Lo, Y. Xie and H. F. Schaefer III, ${ }^{13} \mathrm{C}$ NMR Relaxation Study of Molecular Motions in Tetraphenyltin and Tetra(p-tolyl)tin in Solution, J. Phys. Chem. A, 2005, 109, 12059-12063.

54 W. A. Mellink and R. Kaptein, Determination of the methyl group rotation energy barrier in some substituted tricyclo [3.1.0.02,6] hexanes by carbon-13 spinlattice relaxation, Org. Magn. Reson., 1980, 13, 279-281.

55 I. D. Campbell and R. Freeman, Influence of cross-relaxation on NMR spin-lattice relaxation times, J. Magn. Reson., 1973, 11, 143-162.

56 J. J. M. Ramos, C. A. M. Afonso and L. C. Branco, Glass Transition Relaxation and Fragility in Two Room Temperature Ionic Liquids, J. Therm. Anal. Calorim., 2003, 71, 659-666.

57 G. Jarosz, M. Mierzwa, J. Zioło, M. Paluch, H. Shirota and K. L. Ngai, Glass Transition Dynamics of RoomTemperature Ionic Liquid 1-Methyl-3trimethylsilylmethylimidazolium Tetrafluoroborate, J. Phys. Chem. B, 2011, 115, 12709-12716.

58 O. Yamamuro, Y. Minamimoto, Y. Inamura, S. Hayashi and H. Hamaguchi, Heat capacity and glass transition of an ionic liquid 1-butyl-3-methylimidazolium chloride, Chem. Phys. Lett., 2006, 423, 371-375.

59 H. Tokuda, K. Hayamizu, K. Ishii, M. A. B. H. Susan and M. Watanabe, Physicochemical properties and structures of room temperature ionic liquids. 1. Variation of anionic species, J. Phys. Chem. B, 2004, 108, 16593-16600.

60 H. Tokuda, K. Hayamizu, K. Ishii, M. A. B. H. Susan and M. Watanabe, Physicochemical properties and structures of room temperature ionic liquids. 2. variation of alkyl chain length in imidazolium cation, J. Phys. Chem. B, 2005, 109, 6103-6110.

61 H. Tokuda, K. Ishii, M. A. B. H. Susan, S. Tsuzuki, K. Hayamizu and M. Watanabe, Physicochemical properties and structures of room-temperature ionic liquids. 3. Variation of cationic structures, J. Phys. Chem. B, 2006, 110, 2833-2839.

62 T. M. Duncan, A Compilation of Chemical Shift Anisotropies, Farragut Press, Chicago, 1990.

63 G. W. Driver, Y. Huang, A. Laaksonen, T. Sparrman, Y. L. Wang and P. O. Westlund, Correlated/non-correlated ion dynamics of charge-neutral ion couples: The origin of 
ionicity in ionic liquids, Phys. Chem. Chem. Phys., 2017, 19, 4975-4988.

64 V. V Matveev, D. A. Markelov, V. I. Chizhik, P. Ingman and E. Lähderanta, Molecular mobility of counterion functional groups in ionic liquid 1-ethyl-3-methylimidazolium acetate according to ${ }^{1} \mathrm{H}$ and ${ }^{13} \mathrm{C}$ NMR relaxation data, Russ. Chem. Bull., 2013, 62, 1985-1990.

65 R. C. Remsing, J. L. Wildin, A. L. Rapp and G. Moyna, Hydrogen bonds in ionic liquids revisited: (35/37)Cl NMR studies of deuterium isotope effects in 1- $n$-butyl-3methylimidazolium chloride, J. Phys. Chem. B, 2007, 111, 11619-11621.

66 K. Noack, P. S. Schulz, N. Paape, J. Kiefer, P. Wasserscheid and A. Leipertz, The role of the $\mathrm{C} 2$ position in interionic interactions of imidazolium based ionic liquids: a vibrational and NMR spectroscopic study, Phys. Chem. Chem. Phys., 2010, 12, 14153-14161.

67 K. Dong, S. Zhang and J. Wang, Understanding the Hydrogen Bonds in Ionic Liquids and their Roles in Properties and Reactions, Chem. Commun., 2016, 52, 67446764.

68 J.-F. Huang, P.-Y. Chen, I. W. Sun and S. P. Wang, NMR evidence of hydrogen bonding in 1-ethyl-3methylimidazolium-tetrafluoroborate room temperature ionic liquid, Inorg. Chim. Acta, 2001, 320, 7-11.

69 A. Wulf, K. Fumino, D. Michalik and R. Ludwig, IR and NMR Properties of Ionic Liquids: Do They Tell Us the Same Thing?, ChemPhysChem, 2007, 8, 2265-2269.

70 A. D. Headley and N. M. Jackson, The effect of the anion on the chemical shifts of the aromatic hydrogen atoms of liquid 1-butyl-3-methylimidazolium salts, J. Phys. Org. Chem., 2002, 15, 52-55.

71 P. A. Hunt, C. R. Ashworth and R. P. Matthews, Hydrogen bonding in ionic liquids, Chem. Soc. Rev., 2015, 44, 12571288.

72 C. W. N. Cumper, The relation between carbon-hydrogen bond lengths and bond angles, Trans. Faraday Soc., 1958, 54, 1261.

73 J. H. Antony, D. Mertens, T. Breitenstein, A. Dölle, P. Wasserscheid and W. R. Carper, Molecular structure, reorientational dynamics, and intermolecular interactions in the neat ionic liquid 1-butyl-3-methylimidazolium hexafluorophosphate, Pure Appl. Chem., 2004, 76, 255-261.

74 S. M. Green, M. E. Ries, J. Moffat and T. Budtova, NMR and Rheological Study of Anion Size Influence on the Properties of Two Imidazolium-based Ionic Liquids, Sci. Rep., 2017, 7, 1-12.

75 C. S. Lovell, A. Walker, R. A. Damion, A. Radhi, S. F. Tanner, T. Budtova and M. E. Ries, Influence of Cellulose on Ion Diffusivity in 1-Ethyl-3-Methyl-Imidazolium Acetate Cellulose Solutions, Biomacromolecules, 2010, 11, 2927-2935.

76 K. S. Han, S. Li, E. W. Hagaman, G. A. Baker, P. Cummings and S. Dai, Rotational and Translational Dynamics of $\mathrm{N}$ Butyl- $N$-methylpiperidinium Trifluoromethanesulfonimide Ionic Liquids Studied by NMR and MD Simulations, $J$. Phys. Chem. C, 2012, 116, 20779-20786.
77 J. Hou, Z. Zhang and L. A. Madsen, Cation/Anion Associations in Ionic Liquids Modulated by Hydration and Ionic Medium, J. Phys. Chem. B, 2011, 115, 4576-4582.

78 W. R. Carper and C. E. Keller, Direct Determination of NMR Correlation Times from Spin-Lattice and Spin-Spin Relaxation Times, J. Phys. Chem. A, 1997, 101, 3246-3250.

79 Y. H. Zhao, M. H. Abraham and A. M. Zissimos, Fast Calculation of van der Waals Volume as a Sum of Atomic and Bond Contributions and Its Application to Drug Compounds, J. Org. Chem., 2003, 68, 7368-7373.

80 E. McLaughlin, Viscosity and self-diffusion in liquids, Trans. Faraday Soc., 1959, 55, 28-38.

81 T. Köddermann, R. Ludwig and D. Paschek, On the Validity of Stokes-Einstein and Stokes-Einstein-Debye Relations in Ionic Liquids and Ionic-Liquid Mixtures, ChemPhysChem, 2008, 9, 1851-1858.

82 C. K. Larive, M. Lin, B. S. Kinnear, B. J. Piersma, C. E. Keller and W. R. Carper, 13C and 27Al NMR Relaxation, Viscosity, and $1 \mathrm{H}$ Diffusion Studies of an Ethylaluminum Dichloride Melt, J. Phys. Chem. B, 1998, 102, 1717-1723.

83 A. Martinelli, M. Maréchal, Å. Östlund and J. Cambedouzou, Insights into the interplay between molecular structure and diffusional motion in 1-alkyl-3-methylimidazolium ionic liquids: A combined PFG NMR and X-ray scattering study, Phys. Chem. Chem. Phys., 2013, 15, 5510-5517.

84 A. Strate, T. Niemann, D. Michalik and R. Ludwig, When Like Charged Ions Attract in Ionic Liquids: Controlling the Formation of Cationic Clusters by the Interaction Strength of the Counterions, Angew. Chem., Int. Ed., 2017, 56, 496-500.

85 T. Niemann, D. Zaitsau, A. Strate, A. Villinger and R. Ludwig, Cationic clustering influences the phase behaviour of ionic liquids, Sci. Rep., 2018, 8, 14753.

86 R. Kimmich and E. Anoardo, Field-cycling NMR relaxometry, Prog. Nucl. Magn. Reson. Spectrosc., 2004, 44, 257-320.

87 A. Ordikhani Seyedlar, S. Stapf and C. Mattea, Nuclear magnetic relaxation and diffusion study of the ionic liquids 1-ethyl- and 1-butyl-3-methylimidazolium bis(trifluoromethylsulfonyl)imide confined in porous glass, Magn. Reson. Chem., 2019, 57, 818-828.

88 D. Kruk, M. Wojciechowski, S. Brym and R. K. Singh, Dynamics of ionic liquids in bulk and in confinement by means of ${ }^{1} \mathrm{H}$ NMR relaxometry-BMIM-OcSO 4 in an $\mathrm{SiO}_{2}$ matrix as an example, Phys. Chem. Chem. Phys., 2016, 18, 23184-23194.

89 D. Kruk, M. Wojciechowski, Y. L. Verma, S. K. Chaurasia and R. K. Singh, Dynamical properties of EMIM-SCN confined in a $\mathrm{SiO}_{2}$ matrix by means of ${ }^{1} \mathrm{H}$ NMR relaxometry, Phys. Chem. Chem. Phys., 2017, 19, 32605-32616.

90 K. Pilar, A. Rua, S. N. Suarez, C. Mallia, S. Lai, J. R. P. Jayakody, J. L. Hatcher, J. F. Wishart and S. Greenbaum, Investigation of Dynamics in BMIM TFSA Ionic Liquid through Variable Temperature and Pressure NMR Relaxometry and Diffusometry, J. Electrochem. Soc., 2017, 164, H5189-H5196.

91 A. E. Khudozhitkov, P. Stange, A. M. Bonsa, V. Overbeck, A. Appelhagen, A. G. Stepanov, D. I. Kolokolov, D. Paschek and R. Ludwig, Dynamical heterogeneities in ionic liquids 
as revealed from deuteron NMR, Chem. Commun., 2018, 54, 3098-3101.

92 D. Kruk, R. Meier, A. Rachocki, A. Korpała, R. K. Singh and E. A. Rössler, Determining diffusion coefficients of ionic liquids by means of field cycling nuclear magnetic resonance relaxometry, J. Chem. Phys., 2014, 140, 244509.
93 K. Hayamizu, S. Tsuzuki, S. Seki and Y. Umebayashi, Multinuclear NMR studies on translational and rotational motion for two ionic liquids composed of BF4 anion, $J$. Phys. Chem. B, 2012, 116, 11284-11291. 